\title{
Thermodynamic cycles in the stratosphere
}

Article

Accepted Version

Ruggieri, P., Ambaum, M. and Nycander, J. (2020)

Thermodynamic cycles in the stratosphere. Journal of the Atmospheric Sciences, 77 (6). pp. 1897-1912. ISSN 15200469 doi: https://doi.org/10.1175/JAS-D-19-0188.1 Available at https://centaur.reading.ac.uk/89401/

It is advisable to refer to the publisher's version if you intend to cite from the work. See Guidance on citing.

To link to this article DOI: http://dx.doi.org/10.1175/JAS-D-19-0188.1

Publisher: American Meteorological Society

All outputs in CentAUR are protected by Intellectual Property Rights law, including copyright law. Copyright and IPR is retained by the creators or other copyright holders. Terms and conditions for use of this material are defined in the End User Agreement.

www.reading.ac.uk/centaur

\section{CentAUR}

Central Archive at the University of Reading

Reading's research outputs online 


\title{
Thermodynamic cycles in the stratosphere
}

\author{
Paolo Ruggieri* \\ Fondazione Centro Euro-Mediterraneo sui Cambiamenti Climatici, Bologna, Italy \\ Maarten H. P. Ambaum \\ Department of Meteorology, University of Reading, United Kingdom \\ Jonas Nycander \\ Department of Meteorology, Stockholm University, Sweden
}

${ }_{8}^{*}$ Corresponding author address: Paolo Ruggieri, Centro Euro-Mediterraneo sui Cambiamenti Cli-

9 matici, via C. Berti Pichat 6/2 40127 Bologna, Italy

10 E-mail: paolo.ruggieri@cmcc.it 


\begin{abstract}
11

12

17 is mechanically driven. Here we present a fully thermodynamic analysis of ${ }_{27}$ is mechanically-driven by waves. The wave driving does not modulate the

Large-scale overturning mass transport in the stratosphere is commonly explained through the action of potential vorticity (PV) rearrangement in the flank of the stratospheric jet. Large-scale Rossby waves, with wave activity source primarily in the troposphere, stir and mix PV and an overturning circulation arises to compensate the zonal torque imposed by the breaking waves. In this view, any radiative heating is relaxational and the circulation these phenomena, based on ERA-Interim data. Stream functions in a thermodynamic, log-pressure-temperature space are computed. The sign of a circulation cell in these coordinates directly shows whether it is mechanically driven, converting kinetic energy to potential and thermal energy, or thermally driven, with the opposite conversion. The circulation in the lower stratosphere is found to be thermodynamically indirect, i.e. mechanically driven. In the middle and upper stratosphere thermodynamically indirect and direct circulations coexist, with a prominent semiannual cycle. A part of the overturning in this region is thermally driven, whilst a more variable indirect circulation strength of the thermally direct part of the circulation. This suggests that the basic overturning circulation in the stratosphere is largely thermally driven, while tropospheric waves add a distinct indirect component to the overturning. This indirect overturning is associated with poleward transport of anomalously warm air parcels.
\end{abstract}


The existence of an overturning circulation in the stratosphere was inferred from the observed distribution of chemical species above the tropopause, in particular water vapor (Brewer 1949) and ozone (Dobson 1956). Deduction of Lagrangian velocities from the height-latitude distribution of ${ }_{37}$ such tracers is one approach to diagnose the meridional circulation in the middle atmosphere. ${ }_{38}$ Furthermore, dynamical estimates of stratospheric transport have been developed which helped understand the physical mechanisms driving motion. The currently accepted paradigm is that the stratospheric overturning circulation is the result of the Coriolis force of the overturning circulation compensating for the westward wave torque imposed by breaking Rossby and gravity waves (see e.g. Cohen et al. 2014). Quasi-geostrophic theory led to this identification of wave-mean-flow interaction as the main driver of the overturning circulations, but the introduction of Lagrangian averages in the theory raised awareness of the relation between the actual mass transport in the ${ }_{45}$ stratosphere and diabatic effects (Dunkerton 1978).

${ }_{46}$ A successful approximation to the Lagrangian circulation in this context has been provided by 47 the introduction of the Transformed Eulerian Mean (TEM, see Andrews and McIntyre 1976, 1978; Andrews et al. 1987). This theory offers a framework to diagnose both the wave forcing on the 49 mass transport and the diabatic effects. The net impact of the waves on the mean flow can be explained in terms of the stirring of potential vorticity (PV) by breaking waves which changes the ${ }_{51}$ mean PV gradient, establishing a surf zone (McIntyre and Palmer 1984; Becker and Schmitz 2003; ${ }_{52}$ Scott and Liu 2014) of homogeneous PV in the midlatitude stratosphere.

${ }_{53}$ Progress in this area helped explain the distribution of tracers found by Brewer and Dobson ${ }_{54}$ and contributed to the current perspective on the middle-atmosphere overturning circulation that ${ }_{55}$ is summarised by Plumb (2002). Synoptic waves induce a symmetric circulation (with respect 
to the equator) in the lower-stratosphere with air rising in the tropics and falling in the extratropics. Planetary, quasi-stationary waves perturb the core of the stratosphere, inducing an interhemispheric cell, with upward motion at low latitudes and sinking motion in winter polar latitudes. Gravity waves drive a global cell in the mesosphere. The stratosphere can be thought of as divided into 4 regions with specific features, namely the summer extratropics, the tropical stratosphere, the surf zone and the cold pole (see e.g. Butchart 2014).

Overturning circulations in the atmosphere are induced by diabatic heating and by wave-torque (Schneider 2006). The idealised inviscid limit described by Held and Hou (1980) explains the tropospheric Hadley cell implied by non-uniform insolation. A stratospheric analogue (Semeniuk and Shepherd 2001) of this mechanism explains tropical upwelling even in the inviscid limit (Dunkerton 1989). Thermodynamically this circulation is maintained by diabatic heating and produces work, i.e. is thermally driven and thermodynamically direct. Turbulent advection and waves must be invoked to ensure conservation of angular momentum (see e.g. Plumb and Eluszkiewicz 1999; Schneider 2006). This is particularly relevant to the stratosphere where hemispheric cells move equatorial air into the poles, across surfaces of constant angular momentum.

Evidence and consensus have established the role of extra-tropical planetary Rossby waves as major driver of the stratosphere overturning circulation. The mechanism behind a wave driven circulation is often named 'extra-tropical pump', after the work of Holton et al. (1995). A meridional circulation in presence of breaking waves is deducible from the TEM equations, and further clarification in this regard was provided by the formulation of the downward control principle (Haynes et al. 1991), which showed that any steady, wave-driven vertical motion at a certain level in the stratosphere can be predicted by the wave-force exerted above that level.

In the stratosphere, waves move air masses adiabatically out of radiative equilibrium and diabatic heating brings the system back to radiative equilibrium, attempting to restore the unperturbed 
equator-to-pole PV gradient. If the wave-induced adiabatic motion increases the potential energy, it requires work to be maintained, and is damped by heating and cooling. The circulation is then mechanically driven and thermally indirect (Shepherd 2007). However, the wave-induced adiabatic motion may also convert potential and thermal energy to kinetic energy by flattening the isentropic surfaces. Thermodynamically, such a circulation is thermally driven, even if waves are a necessary ingredient.

In this study a thermodynamic analysis of the stratospheric overturning circulation in $\log$ (pressure)-temperature coordinates is presented. Thermodynamic coordinates have been studied and applied in oceanography (Zika et al. 2012; Nurser and Lee 2004) and the analysis presented by Nycander et al. (2007) is an example of a fully thermodynamic description of the global oceanic circulation. In the atmosphere, thermodynamic coordinates have typically been restricted to their use as a vertical coordinate, e.g. pressure or potential temperature, while keeping latitude as horizontal coordinate. For example, isentropic coordinates yield a good estimate of the lagrangian motion in the stratosphere. Indeed the meridional stream function in potential temperature-latitude coordinates shows two cells extending from tropical regions to high latitudes (Kållberg et al. 2005) in agreement with the TEM overturning circulation. Examples of fully thermodynamic descriptions of the atmospheric circulation can be found in scientific literature (e.g. Pauluis et al. 2010; Kamieniecki et al. 2018), but a thermodynamic analysis specifically designed for the stratosphere circulation has not been used previously.

Here we apply a fully thermodynamic set of coordinates to describe the state of the stratosphere and its variability. A major advantage is that this offers a possibility to use a definition of 'mechanically' and 'thermally' forced circulations that agrees with fundamental thermodynamics. According to this definition, the circulation is mechanically forced if it converts mechanical energy to heat, and thermally forced if it converts heat to mechanical energy. Note that "mechan- 
ically driven" is not necessarily the same thing as "wave driven" in stratospheric research, where it is common to regard the meridional circulation as wave driven if it is proportional to the eddy terms in a simplified analytic model. In thermodynamics, a heat engine is thermally forced and a refrigerator is mechanically forced. By contrast, the meridional circulation in an idealized model of the atmosphere may be proportional to friction or viscosity, although friction is always a sink of kinetic energy and cannot be a forcing agent from a thermodynamic point of view. One problem with the term "wave-driven" is that it is not straightforward to diagnose the connection between the eddy terms and meridional circulation in a three-dimensional simulation, or in observational data. It is therefore unclear how to identify which parts of the circulation are wave-driven, and which parts are not.

By using thermodynamic coordinates, we can identify what parts of the stratospheric overturning circulation are mechanically driven, with a passive adjustment of diabatic effects, and what parts are thermally driven. In both cases, waves and eddies may be an essential part of the dynamics, but in the former case their energy is transported from other regions by the waves, while in the latter case the eddies extract most of their energy from the local mean flow. However, our analysis does not distinguish between eddies and mean flow.

Moreover, the magnitude of this energy conversion is obtained directly by integrating the stream function over the cell. At the same time we will find that much geometric information is implicitly maintained. This is due to the simple observation that pressure decreases with altitude, while temperature, broadly, decreases with latitude.

In section 2 , the thermodynamic stream function is presented, and its connection to the conversion between different kinds of energy is derived. Section 3 presents the numerical implementation of the calculations, and the reanalysis data used. In section 4, results are presented, looking in particular at the comparison of months with strong and weak planetary wave forcing and at the 
seasonal cycle. Finally, section 5 discusses the main findings of this study focusing on how they can enrich the conventional interpretation of stratospheric motion.

\section{Thermodynamic stream function}

We begin by analysing the energetics of the primitive equations for an ideal gas in pressure coordinates. They are

$$
\begin{gathered}
\frac{\mathrm{d} \mathbf{v}}{\mathrm{d} t}+f \hat{z} \times \mathbf{v}+\nabla \phi=\mathbf{F} \\
\frac{\partial \phi}{\partial p}=-\alpha \\
\nabla \cdot \mathbf{v}+\frac{\partial \omega}{\partial p}=0 \\
c_{v} \frac{\mathrm{d} T}{\mathrm{~d} t}+p \frac{\mathrm{d} \alpha}{\mathrm{d} t}=\frac{1}{g} \frac{\partial \Phi_{E}}{\partial p}+Q \\
p \alpha=R T
\end{gathered}
$$

Here $\mathbf{v}$ is the horizontal velocity, $f$ the Coriolis parameter, $\nabla$ the horizontal gradient operator along isobaric surfaces, $\phi$ the geopotential, $\mathbf{F}$ the viscous force, $\alpha$ the specific volume, $\Phi_{E}$ the vertical non-advective energy flux by turbulent mixing, $Q$ represents the internal sources and sinks of energy due to radiation and latent heat, $T$ and $p$ are respectively temperature and pressure, $\omega=\mathrm{d} p / \mathrm{d} t$ is the vertical velocity in pressure coordinates, and

$$
\frac{\mathrm{d}}{\mathrm{d} t}=\frac{\partial}{\partial t}+\mathbf{v} \cdot \nabla+\omega \frac{\partial}{\partial p}
$$

Define the mass element $\mathrm{d} m=\rho \mathrm{d} V=\mathrm{d} \mathbf{r d} p / g$, where $\mathrm{d} \mathbf{r}$ is a horizontal surface element, $\rho$ the mass density, $V$ volume and $g$ the gravity acceleration. The kinetic energy is then given by

$$
K=\int \frac{|\mathbf{v}|^{2}}{2} \mathrm{~d} m
$$

the internal energy by

$$
I=\int c_{v} T \mathrm{~d} m
$$


and the potential energy by

$$
U=\int \phi \mathrm{d} m
$$

The integrals are here taken over the whole atmosphere. Assuming that the bottom surface is flat, with $\phi=0$ at the surface, we also have

$$
U=-\int p \frac{\partial \phi}{\partial p} \mathrm{~d} m=\int p \alpha \mathrm{d} m
$$

By using eq. (5) we obtain

$$
U=\frac{R}{c_{v}} I
$$

we obtain

$$
\frac{\mathrm{d}}{\mathrm{d} t}(U+I)=S-C,
$$

where $S$ is the total heat source,

$$
S=\int Q \mathrm{~d} m .
$$

${ }_{144}$ In the terminology of classical thermodynamics, $U+I$ is the enthalpy of the atmosphere. It is also 145 sometimes called the 'total potential energy'. As a result of the hydrostatic approximation, $U$ and 
$I$ are not independent quantities, as seen from eq. (6). Nevertheless, it is possible to diagnose the transfer between $I$ and $U$ by using the definition of the thermodynamic work $W$ :

$$
W=\int p \frac{\mathrm{d} \alpha}{\mathrm{d} t} \mathrm{~d} m
$$

Equation (9) can now be written

$$
\frac{\mathrm{d} U}{\mathrm{~d} t}=W-C
$$

By combining eqs (10) and (12) we obtain

$$
\frac{\mathrm{d} I}{\mathrm{~d} t}=S-W
$$

explicitly showing that $W$ represents the conversion from internal energy to potential energy. The budget equations (7), (12) and (13) are illustrated in the box diagram in Fig. 1. As a result of the hydrostatic approximation, there is no direct energy transfer between $I$ and $K$ without involving $U$. Such a direct transfer is involved in sound waves, which cannot be described by the hydrostatic model (1)-(5).

We now introduce the thermodynamic stream function for mass with specific volume and pressure as coordinates, $\Psi(\alpha, p)$. By definition, $\Psi(\alpha, p)$ is the mass flux through that part of the isobaric surface given by $p$ where the specific volume is greater than $\alpha$. Equivalently, it is the mass flux through the surface where the specific volume is $\alpha$ and the pressure is greater than $p$. The equivalence requires that the atmosphere is in a statistically steady state, so that that the mass distribution on the $(\alpha, p)$-plane is stationary. In this case the mass flux on this plane is nondivergent, and can be represented by a stream function. The thermodynamic stream function is illustrated in Fig. 2.

We will now calculate the thermodynamic work $W$ defined in eq. (11) by integrating over the $(\alpha, p)$-plane. We then need to know the mass $\mathrm{d} m$ in the element $\mathrm{d} \alpha \mathrm{d} p$ shown Fig. 2. This mass 
is given by $\mathrm{d} m=\mathrm{d} \Psi \delta t$, where $\delta t=\mathrm{d} \alpha /(\mathrm{d} \alpha / \mathrm{d} t)$ is the time it takes for the flow to go from $\alpha$ to $\alpha+\mathrm{d} \alpha$, and $\mathrm{d} \Psi=(\partial \Psi / \partial p) \mathrm{d} p$ is the difference of $\Psi$ across the element. We obtain

$$
\mathrm{d} m=\frac{\partial \Psi / \partial p}{\mathrm{~d} \alpha / \mathrm{d} t} \mathrm{~d} \alpha \mathrm{d} p
$$

Using this, eq. (11) gives

$$
W=\int p \frac{\partial \Psi}{\partial p} \mathrm{~d} \alpha \mathrm{d} p=-\int \Psi \mathrm{d} \alpha \mathrm{d} p
$$

${ }_{171}(\alpha, p)$-plane.

The thermodynamic character of the circulation is closely connected to the sign of the vertical advective heat flux $F$. The upward advective heat flux through the pressure surface $p=p_{0}$ is given by

$$
F=-\frac{1}{g} \int_{p=p_{0}} \omega c_{p} T d S
$$

where the partial integration was carried out using the fact that $\Psi \rightarrow 0$ as $p \rightarrow 0$ and $p \rightarrow \infty$.

Below, we will use the temperature $T$ as a coordinate instead of $\alpha$, while pressure is replaced by ' $\log ($ pressure $) ' z=H \ln \left(p_{0} / p\right)$ as the vertical coordinate. This makes little difference, since the contours $T=$ const and $\alpha=$ const coincide on isobaric surfaces. Using $\mathrm{d} T=(p / R) \mathrm{d} \alpha$ and $\mathrm{d} z=-(H / p) \mathrm{d} p$ we obtain

$$
W=\frac{R}{H} \int \Psi \mathrm{d} T \mathrm{~d} z
$$

The sign convention for $\Psi$ is here chosen so that a circulation cell with positive $\Psi$ on the $(T, z)$ plane is anticlockwise, i.e. thermally direct with $W>0$, with warm air advected upward, to lower pressure, and cold air downward. This corresponds to the clockwise circulation in Figure 2 on the y

where $d S$ is a surface element and $c_{p}$ the heat capacity at constant pressure. Consider two isothermal curves on the pressure surface, enclosing the surface element $d S$. The mass flux across this element is $d \psi$, which is the difference between the value of $\psi$ on the two curves, and the advective 
heat flux is $c_{p} T d \psi$. We obtain, after a partial integration

$$
F=-\int_{p=p_{0}} c_{p} T d \Psi=\int_{p=p_{0}} c_{p} \Psi d T
$$

Thus, the advective heat flux is obtained directly from the thermodynamic stream function, by integrating $\psi(T, p)$ along the line $p=p_{0}$. If the circulation is thermally driven, and $\Psi$ hence positive, heat is advected upwards by the circulation.

If $\Psi$ is positive, $W$ and $C$ in Figure 1 are both positive, i.e. internal and potential energy is converted to kinetic energy. (Note that $C=W$ if the circulation is steady.) A thermally indirect circulation cell, with negative $\Psi$, on the other hand, converts kinetic energy to internal and potential energy by adiabatic compression.

Thus, the advantage with the thermodynamic stream function is that the sign of $\Psi$ immediately shows whether the circulation is thermally forced or mechanically forced, using our definition.

The main non-adiabatic effect in the stratosphere is radiation, which relaxes the atmosphere to a stably stratified radiative equilibrium. Consider a wave that propagates on this background stratification. If a wave crest pushes air upwards, the air cools adiabatically, and is then warmed by radiation. The result is that the anomalously cold air is advected irreversibly upwards, through an isentropic surface. Similarly, the air in a wave trough that pushes air downwards is anomalously warm, then cooled by radiation, and advected irreversibly downwards. The net result is downward heat advection. Thus, radiation damping of waves leads to a mechanically forced, indirect circulation that converts kinetic energy to internal and potential energy.

However, since the radiative equilibrium has sloping isentropic surfaces, waves may instead extract energy from the background by flattening these surfaces. This is what happens in baroclinic instability. The result is a direct circulation that converts potential and thermal energy to kinetic 
energy. From a thermodynamic point of view it is thermally forced, even if it is mediated by the presence of waves.

The circulation of the atmosphere is ultimately driven by solar heating. Thus, the integral of the thermodynamic stream function over the whole atmosphere must be positive. But there may still exist separate circulation cells with different sign. The kinetic energy required to sustain the circulation in an indirect cell must then be generated in another, thermally forced cell (typically in the troposphere). Such energy transfer between different cells may be achieved by various waves. The purpose of the presented analysis is to provide a definition of thermally-driven and mechanically-driven from a thermodynamic perspective. For the stratosphere, this approach allows to quantify to what extent waves act as a mechanical forcing of the overturning, as is commonly assumed. Indeed, while waves are a necessary ingredient to ensure conservation of angular momentum, to some extent their role is analogous to the role of friction in a steady gravity current down a slope, where the driver is gravitational potential energy and the friction is required to ensure steadiness.

\section{Methodology}

\section{a. Circulation in thermodynamic coordinates}

Results presented in section 4 are based on a computation with reanalysis data of the flow in a temperature-log(pressure) $(T-z)$ space in the stratosphere. The vertical coordinate is defined by $z \equiv H \ln \left(p_{0} / p\right)$ where the reference pressure $p_{0}$ is chosen as $1000 \mathrm{hPa}$, and the temperature scale height $H$ is chosen as $6 \mathrm{~km}$. The flow is defined by the mass flux densities

$$
\begin{aligned}
\Omega(T, z) & \equiv \Phi(T, z) \dot{z}(T, z) \\
\tau(T, z) & \equiv \Phi(T, z) \dot{T}(T, z)
\end{aligned}
$$



231 gridbox, and as

where $\Phi$ is a mass density in $(T, z)$-space and $\dot{z}$ and $\dot{T}$ are mass-weighted tendencies. $\Omega$ is defined

$$
\Omega(T, z)=\iint_{V} \delta(T(\mathbf{r})-T) \delta(z(\mathbf{r})-z) \dot{z}(\mathbf{r}) \rho(\mathbf{r}) \mathrm{d} \mathbf{r},
$$

where $\mathbf{r}$ is integrated over all of the domain $V$, and where $\rho$ is the usual (geometric) mass density. Other variables in $(T, z)$ space are computed analogously; the mass density $\Phi$ is computed by replacing $\dot{z}(\mathbf{r})$, above, with unity. $\tau$ can be computed replacing $\dot{z}(\mathbf{r})$ in Eq. 17 with the lagrangian tendency of temperature $(\dot{T}(\mathbf{r}))$.

Assuming that the flow defined by $\Omega$ and $\tau$ is non-divergent (this is a consequence of the diagnosed flow corresponding to a broadly steady state, so that the mass distribution $\Phi$ is essentially constant in time) a stream function can be defined as the integral of $\mathrm{d} \Psi=\tau \mathrm{d} z-\Omega \mathrm{d} t$. More specifically, for the Earth's atmosphere, $\Phi$ can be regarded as the total atmospheric mass at temperature $T$ and pressure $p, \dot{z}(T, z)$ and $\dot{T}(T, z)$ are respectively the mass-weighted, lagrangian tendency of the logarithm of pressure and of temperature, again at temperature $T$ and pressure $p$. With these premises, $\Psi$ can be computed everywhere if either $\Omega$ or $\tau$ are known.

The definition of $\Omega$ for a discrete, longitude-latitude grid on a pressure level $p$ is:

$$
\Omega(T, z)=\sum_{l, m} \frac{\dot{z}_{l m} M_{l m} \delta_{T_{l m}, T}}{\Delta z \Delta T} .
$$

where the sum is done over longitudes 1 and latitudes $\mathrm{m}, M_{l m}$ is the mass represented by the

$$
\delta_{T_{l m}, T}= \begin{cases}1, & \text { if } T-\Delta T / 2<T_{l m}<T+\Delta T / 2 \\ 0, & \text { elsewhere. }\end{cases}
$$

$\Delta z$ and $\Delta T$ in eq. 18 are the spacing in the discretised thermodynamic space.

Assuming hydrostatic balance, the mass of the air in each gridbox can be expressed as the product of the gridbox area $\Delta A_{l m}$ and mass per unit area $\Delta p / g$. This decomposition is useful 
because the underlying data are organised along pressure surfaces representing a fixed pressure thickness $\Delta p$. Further details are written out in the Appendix. Similarly, hydrostatic balance can be used to show that for the log-pressure coordinate $z$ we will have $\dot{z} / \Delta z=-\dot{p} / \Delta p$. Substituting in equation 18 and multiplying by $\mathrm{H}$ the mass flux can be written as

$$
\Omega(T, z)=-\sum_{l, m} \frac{\dot{p}_{l m} \Delta A_{l m} \delta_{T_{l m}, T}}{g \Delta T} .
$$

The stream function can be computed by integrating over the $T$-dimension

$$
\Psi(T, z)=-\int_{0}^{T} \Omega\left(T^{\prime}, z\right) \mathrm{d} T^{\prime} .
$$

Densities of mass $(\Phi)$ and latitude $(\Theta)$ have been computed similarly, as reported in the Appendix. The operation introduced by Eq. 20 and 21 corresponds to summing up mass-weighted lagrangian tendencies (trajectories) corresponding to air masses of similar temperature and pressure, and is conceptually analogous to the computation of a stream function in geometric coordinates. In this case, the usual geometric coordinates are replaced by thermodynamic variables. Therefore, $\Omega$ and $\tau$ indicate motion along respectively the vertical (z) and horizontal (T) coordinate of the T-z space that is introduced in Fig. 3.

\section{b. Data}

The analysis presented in this study is based on reanalysis data from ERA-Interim, the European Centre for Medium-Range Weather Forecasts reanalysis (Dee et al. 2011). Fields of temperature, lagrangian pressure tendency, zonal wind and meridional wind are obtained 6-hourly, on a $0.75^{\circ} \times$ $0.75^{\circ}$ regular, longitude-latitude grid on all available pressure levels, for a reference period from September 1994 to August 2015. The circulation in the stratosphere is diagnosed in temperature and log-pressure coordinates on 14 pressure levels between 225 and $1 \mathrm{hPa}$. The temperature spacing $\Delta T$ is constant and set at $3 \mathrm{~K}$, the pressure spacing $\Delta p$ is equal to the vertical spacing of the 
dataset, and typically varies with pressure level. Results presented in Figs. 9-13 are computed for two subsets of the reference period, namely May and June (MJ) and November and December (ND). Since a thermodynamic stream function can only be defined for the global circulation, to identify a correspondence between regions of the geometric space and portions of the thermodynamic space, we have defined 4 sectors, whose boundaries are shown in table 1 , and we have computed mass densities in $T-z$ space for each of these limited areas.

Because the mass fluxes are not completely steady, nor numerically fully conservative, stream functions are computed applying a small correction on the mass flux density. Introducing the average $\langle\ldots\rangle=(\Delta T)^{-1} \int_{0}^{\infty} \ldots d T$, then a corrected mass-flux is defined by

$$
\tilde{\Omega}(T, z)=\Omega(T, z)-\Phi(T, z)\langle\Omega\rangle /\langle\Phi\rangle
$$

which ensures that $\langle\tilde{\Omega}\rangle=0$. The stream function $\Psi$ is then computed using eq. 21 with $\Omega$ replaced by $\tilde{\Omega}$. For pressure levels between 1 and $175 \mathrm{hPa}|\langle\Omega\rangle| /\langle|\Omega|\rangle<0.01$, so the corrections required are of a small magnitude compared to typical diagnosed mass fluxes.

\section{Results}

\section{a. Stratosphere circulation in thermodynamic coordinates}

Figure 3 shows the annual mean stream function $\psi$ in the $\mathrm{T}-\mathrm{z}$ space. Contours in the figure identify streamlines of the motion, with the direction of the motion identified in every point by the vector $(\Omega, \tau)$. This direction is indicated qualitatively by the arrows. Closed streamlines identify thermodynamic cycles, and $\Psi$ defines the mass per unit time flowing in a certain cycle.

At the very bottom, there is a thermally direct cell. This is the uppermost part of the Hadley cell in the troposphere, which is driven by diabatic heating from below. We can then identify three different altitude regions. In the tropopause and lower stratosphere, roughly $225 \mathrm{hPa}-50 \mathrm{hPa}$, 
the entire circulation is thermally indirect, with the warmest air downwelling and the coldest air upwelling (this is the upwelling through the cold point at the tropopause).

In the mid stratosphere, say between $50 \mathrm{hPa}$ and $10 \mathrm{hPa}$, there are two cells. In the direct cell warm air rises in the tropics, and cold air downwells. There is also an indirect cell of greater intensity with downwelling at the highest temperatures. The final region is the upper-stratosphere $(10 \mathrm{hPa}$ and $1 \mathrm{hPa})$ where the indirect cell fades and the circulation turns into predominantly direct. The integral of the stream function $\Psi$ over temperature is proportional to the vertical advective heat flux, as seen from Eq. (15). The heat flux associated with the direct and indirect cells taken individually is shown in Figure 4. The displayed quantity is $\left(c_{p} / A\right) \int \Psi d T$, where $c_{p}$ is the air specific heat at constant pressure and $A$ is the area of the Earth. The heat flux is strongly positive in the troposphere and becomes negative above $200 \mathrm{hPa}$ where the circulation is only indirect. The absolute value of the negative flux in the lower stratosphere reaches a maximum around 125 $\mathrm{hPa}$ and then starts decreasing with height, while the direct component starts being detectable at about $50 \mathrm{hPa}$. Above $20 \mathrm{hPa}$, the direct and indirect components broadly compensate, producing a near-zero heat flux.

Air motion in the stratosphere undergoes substantial seasonal variations driven by the seasonal cycle of radiative forcing and by the seasonal cycle of upward propagating waves. We therefore investigate the variations of the stream function through the year at three pressure levels in the middle of the three regions previously identified. They are: the upper-stratosphere (1-10 hPa) where the direct and indirect cell coexist and have similar mangnitudes, the mid-stratosphere (10$50 \mathrm{hPa}$ ) where the two cells coexist but the indirect one is stronger, and the lower stratosphere (50-225 hPa) where the circulation is only indirect. In Fig. 5 the seasonal cycle of the monthly mean values of the stream function is diagnosed. At $5 \mathrm{hPa}$ (Figure $5 \mathrm{a}-\mathrm{b}$ ), seasonal variations are large (of the order of typical monthly mean values) with a semiannual cycle for both cells: the 
direct cell peaks around the solstices, as expected from the strong meridional gradient of insolation,

while the indirect cell peaks in late boreal winter and early boreal autumn.

Lower in the stratosphere, at $20 \mathrm{hPa}$ (Figure $5 \mathrm{c}-\mathrm{d}$ ), seasonal variations are weaker and two cells are always present, although the direct one is remarkably weak in late equinoctial seasons and the indirect one is weak in boreal summer. The direct cell shows a net semiannual cycle as in the upper stratosphere, whereas the indirect cell shows an annual cycle (Figure 5 e-f).

At $125 \mathrm{hPa}$ the circulation is always thermodynamically indirect, and the seasonal cycle is moderate, with variations of about $15 \%$ of the annual mean. The strength of the cell is modulated from a peak in boreal winter to the minimum in the boreal summer. This finding is in agreement with the annual cycle of the lower branch of the Brewer-Dobson circulation due to the larger seasonal amplitude in the Northern upwelling (see e.g. Plumb 2002; Seviour et al. 2012; Homeyer and Bowman 2013). The root-mean-square vertical mass flux per unit Kelvin, in the right panels, also shows moderate seasonal variations broadly in tandem with the magnitude of the mass stream function.

To quantify the intensity of the circulations associated with the two cells, in Figs 6 and 7 the maximum and minimum values of the stream function are shown as function of the day of the year at the same levels used in Fig. 5. The direct circulation (Fig 6) peaks in the surroundings of the solstices in the mid and upper stratosphere. The intensity of the circulation is comparable in the mid and upper stratosphere and it undergoes a similar modulation through the seasons. In the lower stratosphere a small peak is found only in the late boreal summer. The indirect circulation (Fig 7) instead ranges through three orders of magnitude and shows considerably different features at different levels. It will be shown, in the following section, that the modulation of the intensity of the indirect circulation can be explained by the seasonality of upward propagation of Rossby waves that are also shown to be inadequate to explain the modulation of the direct part. 


\section{b. The effect of wave-torque in the thermodynamic space}

The traditional view of the stratospheric overturning circulation implies a meridional mass displacement induced by large scale waves generated in the troposphere. Figure 8 shows the eddy heat flux $\left[v^{*} T^{*}\right]$ at $100 \mathrm{hPa}$, averaged in the mid-latitudes $\left(40^{\circ}-80^{\circ} \mathrm{N} / \mathrm{S}\right)$ both in the Northern Hemisphere $(\mathrm{NH})$ and the Southern Hemisphere $(\mathrm{SH})$ and their sum. This is a measure of the upward propagation of planetary Rossby waves into the stratosphere, and a strong predictor of PV rearrangement in the stratosphere (Hinssen and Ambaum 2010). The sign of the SH heat flux in this figure has been flipped, because the upward wave activity flux is proportional to the poleward heat flux, and not the northward heat flux (in essence, the corresponding upward Eliassen-Palm flux has a factor proportional to the Coriolis parameter; note also that the poleward heat fluxes are dominant in the midlatitudes).

In the $\mathrm{NH}$ the poleward heat flux peaks in mid boreal winter, whereas in the SH high values are found in late boreal summer and early autumn. The sum of the northern and southern poleward heat flux, i.e. the black line in Figure 8, shows an annual cycle with a short window of weak flux between May and August, and a longer window of high flux peaking in December. Because of the proportionality with the upward Eliassen-Palm flux, this sum can be interpreted as a measure of the total zonal wave-induced torque exerted on the global stratosphere.

The asymmetry between the two hemispheres allows to compare the global stratospheric circulation under similar radiative forcing (insolation) but with very different mechanical forcing (wave-induced torque), as the NH generates more wave activity than the SH in their respective winters. In view of this, May and June (MJ) are used as a reference, unperturbed stratospheric state, and November and December (ND) are used as a perturbed state, where the stratosphere is strongly forced by tropospheric waves. In Figure 9 the mass and vertical mass flux densities 
(respectively $\Phi$ and $\Omega$, defined in section 3) for the two reference periods MJ and ND are shown. Here shadings indicate how much mass is found in the atmosphere at temperature $T$ and pressure $p$, while contours indicate whether the air mass moves predominantly upward (positive sign) or downward (negative sign).

MJ can be regarded as the state of the stratosphere under weak mechanical forcing by planetary Rossby waves. The ensuing dynamics is therefore expected to be dominated by direct radiative forcing, at least in the mid-high stratosphere where the role of these waves is dominant (Plumb 2002). In the lower stratosphere the mass of the atmosphere is distributed over a wide temperature range between $190 \mathrm{~K}$ and $230 \mathrm{~K}$, a fact that is explained by the strong temperature gradients between the tropics, that contain much of the mass of the atmosphere, and the extra-tropics. At these levels, cold air rises in the equatorial regions and warmer air sinks. Above $50 \mathrm{hPa}$ most of the mass is confined in a range of about $10-15 \mathrm{~K}$, with a linear increase with pseudo-height of the temperature with the highest upward mass flux. Downward mass fluxes span a wider temperature range, at cooler temperatures.

ND is influenced more strongly by wave fluxes. It can be seen that in ND motion in the lower stratosphere is qualitatively similar to the unperturbed case, perhaps intensified, while in the mid and upper stratosphere some important changes are found. Air masses are distributed almost symmetrically in temperature with respect to the upward and downward mass fluxes, with downward mass fluxes now also happening at high temperatures.

These differences in the mass flux have important implications for the thermodynamics of the overturning circulation, as confirmed by Figure 10 that shows the stream function $\Psi$, in contours, and the mass-weighted absolute value of latitude $\Theta$, in coloured shading, again for MJ and ND. In this figure contours can be interpreted as in Fig. 3, while shadings provide a qualitative information on the angular distance from the equator (with no distinction between the two hemispheres). 
The circulation in the lower stratosphere is indirect in both cases. Tropical air masses move upward through the cold tropical tropopause region and move downward across a range of higher temperatures and latitudes. In MJ in the upper levels tropical air moves across isentropes in the updraft region found in Figure 9, but moves down at cold temperatures in the mid-latitudes and in the quasi-isothermal polar atmosphere. The motion is predominantly direct, as indicated by the positive sign of $\Psi$ which dominates the upper stratosphere.

Although the tropical portion of the stratosphere is geometrically large, it is thermodynamically confined in a narrow temperature region. The figure also shows that polar air is found at both lower and higher temperatures, but the warm polar air is thermodynamically inactive in the MJ season, as can be seen from the low streamfunction gradients there, signifying slow thermodynamic transformation rates.

The corresponding panel for ND shows that the anomalous downward motion at high temperatures is associated with an indirect circulation that in the thermodynamic space appears as an expansion of the lower tropical indirect branch into the upper levels. In this indirect cell, mid and high latitude warm air moves downward in a large band between 240 and $285 \mathrm{~K}$. As shown later, this warm air is found in both hemispheres, at temperatures substantially larger than the zonal mean.

Figure 11 can help link these results with the geometric space. For MJ, the reference state, in the lower levels, the tropical stratosphere is colder than the mid-latitudes. In the upper levels the warm hemisphere is broadly isothermal, whereas the cold hemisphere shows strong temperature gradients in the mid-latitudes. In ND, the cold pole is warmer than in MJ, and stronger temperature gradients are found in the warm hemisphere.

Although there is no unequivocal correspondence between the thermodynamic space and the zonally averaged temperature, in MJ the geometric interpretation is perhaps straightforward: The 
indirect cell in the lower stratosphere is attributable to overshooting convection or to the lower branch of the Brewer-Dobson circulation. It is, to a great extent, symmetric between the two hemispheres. Figure 11 shows that the equatorial air is on average colder than polar and midlatitude air. As seen in Figure 10, the air moves upward through the cold tropical tropopause in a confined region of the $T-z$ space, and moves downward in a thermodynamically broader region, corresponding mainly to the mid-latitudes.

The direct circulation starts being detectable at about $50 \mathrm{hPa}$, which is the level where Figure 11 shows the inversion of the equator-to-pole temperature gradient in the cold hemisphere. At these levels, equatorial air is at intermediate temperatures, between a warm pole, which is inactive, and a cold pole, which is active and corresponds to the descending branch of the direct cell. Comparing Figs. 10 and 11 it can be concluded that in ND the indirect circulation in the mid stratosphere associated with wave-forcing involves temperatures that are typical or higher than the zonal mean temperature of the warm hemisphere. In fact, the portion of the $T-z$ space with highest temperatures is a combination of extra-tropical air in the winter hemisphere at temperatures much higher than the climatological zonal mean, and air in the warm hemisphere, as shown by Figure 12 and 13.

Figure 12 shows mass densities of four regions of the atmosphere defined in table 1. Equatorial air is colder than the rest of the atmosphere in the lower stratosphere but at higher levels the lowest temperatures are found at the cold pole. The tropics and warm extratropics span a narrow temperature range at constant pressure, while the cold pole and surf zone span a much wider range. In presence of waves (ND), a part of the mass of the cold pole and of the surf zone is shifted to very high temperatures that are found typically in the warm hemisphere.

This is further investigated in the analysis of the $10 \mathrm{hPa}$ layer presented in Figure 13. Figure 13a shows the mass density in ND in temperature space for two regions, the warm extratropics and the 
combination of cold pole and surf zone (the cold extratropics) defined as in table 5. This panel demonstrates that the wide temperature range spanned by air in the cold extratropics, at constant pressure, is indeed compatible with a small portion (note the logarithmic scale) of high temperature air in the winter extratropics. The mass-weighted mean vertical velocity, shown in Figure 13b (note that negative corresponds to downward), indicates downward motion at any temperature in the cold extratropics. After a threshold temperature, downwelling becomes stronger as temperature increases. Downward motion in the warm extratropics is weaker and upwelling is found around $225 \mathrm{~K}$. These panels of Figure 13 are useful to interpret the mass flux $(\Omega)$ shown in Figure 13c, which is equal to $-\partial \Psi / \partial T$.

The extratropics in both hemispheres have predominantly downward motion for temperatures higher than $230 \mathrm{~K}$, which corresponds to the descending branch of the indirect circulation (see Figure 10). It can be concluded that the downwelling branch of the thermally indirect cell in the upper stratosphere in ND is associated with: 1) a small fraction of air in the cold hemisphere, "shifted" to very high temperatures, that have a large downward velocity and 2) larger air masses in the warm hemisphere, whose temperature is slightly larger than the zonal mean temperature in the region, with a relatively weak downward motion. The coexistence of these two distinct branches is consistent with the presence of the poleward heat flux at the tropopause found in Fig. 8.

Figure 14 synthesises the above findings on the effect of large scale Rossby waves in the T-z space by showing the anomalous (ND minus MJ) stream function. For the upper stratosphere, this can be interpreted as the thermodynamic stream function forced by Rossby wave breaking in the stratosphere. We can see that the mechanical forcing of the breaking Rossby waves maintains an anomalous indirect circulation with relatively mild air rising in the tropics and warm air sinking in extratropical regions. In Lagrangian terms, it shifts extra-tropical masses in the $T-z$ space from cold to warm regions (Figs. 9 and 12), it intensifies the upward equatorial branch of the 
overturning circulation, and induces a thermodynamically indirect motion that converts kinetic energy to potential energy (Fig. 14).

\section{Concluding remarks}

The thermodynamic properties of the overturning circulation in the stratosphere have been analysed. Stream functions in a temperature-log(pressure) thermodynamic space have been computed with realistic data from an atmospheric reanalysis. The stream function $\Psi$ detects the thermodynamically active component of the circulation (for instance, air rising and sinking at the same temperature and pressure would result in a net zero mass flux in this coordinates system). It is clear that the coordinate system potentially loses geometric information although some obvious geometric information is maintained: pressure reduces with altitude, and temperature in the tropics has a small range which is easily located in temperature-log(pressure) space. An important advantage of this approach is the possibility to quantify whether the circulation converts thermal and potential energy to kinetic energy, or the other way around. This advantage has proved to be particularly appropriate for the stratosphere system considering that the mechanisms discussed in section 1 and 2 imply the existence of both kinds of circulation.

The analysis clearly shows the coexistence of two cells, a direct cell such that:

- it is confined to the mid and upper stratosphere (above $50 \mathrm{hPa}$ )

- the associated circulation peaks around the solstices (Fig. 5)

- the associated circulation scales weakly and inversely with the magnitude of wave injection (i.e. it is typically weaker when waves are stronger, Fig. 14 )

- it produces work at the rate of about $7 \mathrm{TW}$ in the annual mean

- it has a maximum at about $10 \mathrm{hPa}$ and $225 \mathrm{~K}$ in the annual mean (Fig. 3)

- it has similar values at different pressure levels 
- by virtue of the sign in the z-T space it implies conversion of potential energy to kinetic energy (Eq. 14)

and an indirect cell such that:

- it spans the whole vertical structure of the stratosphere

- the associated circulation peaks at different levels in different periods of the years, but is typically strongest in late winter and summer (Fig. 6)

- the associated circulation scales with the magnitude of wave injection (Fig. 14)

- it requires work to be maintained at the rate of about $137 \mathrm{TW}$ in the annual mean (7 TW above $50 \mathrm{hPa})$

- it is maximum in the proximity of the tropopause and $200 \mathrm{~K}$ in the annual mean

- decreases monotonically with height, spanning three order of magnitudes between 225 and 1 $\mathrm{hPa}$

- by virtue of the sign in the z-T space it implies conversion of kinetic energy to potential energy (Eq. 14)

- involves also motion that happens at temperatures that are very different from the zonal mean (Figs. 9-11)

The thermodynamic description of motion in the stratosphere yields an estimate of tropical upwelling that ranges from about $8.1 \times 10^{9} \mathrm{Kg} / \mathrm{s}$ in ND to $5.1 \times 10^{9} \mathrm{Kg} / \mathrm{s}$ in MJ, which is broadly consistent with previous estimates (e.g. Seviour et al. 2012, Fig. 6).

The diagnostics presented in Section 4 offer a thermodynamic picture of the qualitative difference between the lower and upper stratosphere. The lower stratosphere is always dominated by a shallow indirect motion with weak seasonal variations. In the upper stratosphere, say above $50 \mathrm{hPa}$, the direct and indirect components are both present with varying relative and total strength: 
the underlying circulation in the upper stratosphere is thermodynamically direct, while an indirect anomaly is imposed by mechanical wave forcing; when the wave forcing is strong, the indirect component dominates the circulation in parts of thermodynamic space, in particular at anomalously high temperatures in $T-z$ space (which, geometrically, are found in both the warm and the cold hemisphere).

The downward mass flux for the direct branch happens geometrically in the cold winter hemisphere at cold temperatures, whereas downward motion in the indirect branch is found in both hemispheres at warm temperatures. Both the direct and the indirect component imply crossisentropic flow, as they must to close the circulation thermodynamically.

The thermodynamic analysis presented in this study is focused on overturning motion in the stratosphere only but it has been applied also in the troposphere, where it reveals the thermally driven, direct Hadley cell (not shown). It should be noted anyway that below $500 \mathrm{hPa}$ the correction introduced by Eq. 22 becomes relatively large even if the presence of orography is taken into account.

The indirect cell between the tropopause and the $50 \mathrm{hPa}$ layer indicates conversion from kinetic energy to potential energy, and requires a net flux of eddy kinetic energy to be maintained. A reasonable explanation is that the kinetic energy can be supplied for the lowermost part by breaking small scale Rossby waves (Plumb 2002) and by convective overshooting (Fueglistaler et al. 2009). Overshooting convection (i.e. essentially by the inertia of upwelling air) and gravity waves generated by deep convection (Yu et al. 2019) may therefore be important for a part of the annual mean indirect flow in the lower stratosphere. This view is supported by observations that link cold anomalies at the tropical tropopause to deep convection (Gettelman et al. 2002; Schoeberl et al. 2019; Johnston et al. 2018). On the other hand, even models that have no convection up to the cold point manage to describe the thermal structure of this region well (Gettelman and Birner 2007). 
The absence of a thermally driven cell in the lower stratosphere is consistent with findings of Semeniuk and Shepherd (2001). The lack of a semiannual cycle and the peak of the indirect cell intensity in a solstice season (Figure 5) indicate that it is unlikely that a direct component here is masked by a stronger indirect one.

Being an inertial mechanism with a source in the troposphere, convective overshooting becomes less relevant at higher altitudes, in the middle stratosphere; similarly small-scale (synoptic) Rossby waves are filtered out by the lower layers above the tropopause. Here, large-scale Rossby waves have a major role, as the indirect component in the mid-stratosphere is absent when forcing from these waves is absent. Breaking Rossby waves act as an "extratropical wave pump" (Holton et al. 1995), inducing poleward motion to balance the horizontal shear of zonal momentum flux. However, proportionality between the magnitude of the indirect cell and tropospheric wave propagation is not straightforward: seasonal variations in the vertical distribution of zonal mean zonal wind (not shown) suggest that, by Charney-Drazin filtering, the indirect cell in the uppermost part of the stratosphere is well controlled by individual NH and SH heat flux in solstice seasons. In intermediate seasons and far from the upper stratosphere (approximately below $5 \mathrm{hPa}$ ), it is controlled by the total heat flux (i.e. NH plus $\mathrm{SH}$ ). The direct component is dominant around the solstices, and it shows a semiannual cycle at all levels.

Overall, the perspective summarised by Plumb (2002) can be recovered in the $T-z$ description of the circulation. However, the present analysis emphasises the energetics of the circulation and highlights the fact that the basic part of the circulation is thermally forced, and that, when they are strong, breaking Rossby waves add a thermodynamically independent mechanically driven component.

Comparison with other and larger datasets may help discern robust features and highlight differences between reanalyses that have been pointed out by Abalos et al. (2015). Similarly, the 
${ }_{546}$ computed as

$$
M_{l m}=\left|\frac{\Delta p \Delta A_{l m}}{g}\right|=\left|\frac{a^{2} \Delta p \Delta \phi_{l} \Delta \theta_{m} \cos \theta_{m}}{g}\right|
$$

${ }_{547}$ Here $a$ is the Earth's radius, $\theta$ is latitude, $\phi$ is longitude, $\Delta A_{l m}$ is the area of the grid cell. The mass ${ }_{548}$ density in $T-z$ space is defined as

$$
\Phi(T, z)=\sum_{l, m} \frac{M_{l m} \delta_{T_{l m}, T}}{\Delta z \Delta T}
$$

${ }_{549}$ Logarithm of mass density $\Phi$, displayed in Figure 12 , is $\log \left(\frac{\Phi}{\langle\Phi\rangle_{\text {top }}}\right)$ where $\langle\Phi\rangle_{\text {top }}$ is the mass

${ }_{551}$ latitude of air masses in $T-z$ space have been computed as

$$
\Theta(T, z)=\frac{\sum_{l, m}\left|\theta_{l m}\right| M_{l m} \delta_{T_{l m}, T}}{\sum_{l, m} M_{l m} \delta_{T_{l m}, T}}
$$

${ }_{552} \Omega, \Psi, \Theta$ are computed as functions of time and then time-averaged. 


\section{References}

Marta Abalos, Bernard Legras, Felix Ploeger, and William J Randel. Evaluating the advective brewer-dobson circulation in three reanalyses for the period 1979-2012. Journal of Geophysical Research: Atmospheres, 120(15):7534-7554, 2015.

D G Andrews and ME McIntyre. An exact theory of nonlinear waves on a lagrangian-mean flow. Journal of Fluid Mechanics, 89(4):609-646, 1978.

David G Andrews, James R Holton, and Conway B Leovy. Middle atmosphere dynamics. Number 40. Academic press, 1987.

DG Andrews and Mo E McIntyre. Planetary waves in horizontal and vertical shear: The generalized eliassen-palm relation and the mean zonal acceleration. Journal of the Atmospheric

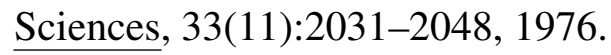

Erich Becker and Gerhard Schmitz. Climatological effects of orography and land-sea heating contrasts on the gravity wave-driven circulation of the mesosphere. Journal of the Atmospheric Sciences, 60(1):103-118, 2003. doi: 10.1175/1520-0469(2003)060<0103:CEOOAL>2.0.CO; 2.

AW Brewer. Evidence for a world circulation provided by the measurements of helium and water vapour distribution in the stratosphere. Quarterly Journal of the Royal Meteorological Society, 75(326):351-363, 1949.

Neal Butchart. The brewer-dobson circulation. Reviews of geophysics, 52(2):157-184, 2014.

Naftali Y. Cohen, Edwin P. Gerber, and Oliver Bühler. What drives the brewer-dobson circulation? Journal of the Atmospheric Sciences, 71(10):3837-3855, 2014. doi: 10.1175/JAS-D-14-0021. 1. 
D. P. Dee, S. M. Uppala, A. J. Simmons, P. Berrisford, P. Poli, S. Kobayashi, U. Andrae, M. A. Balmaseda, G. Balsamo, P. Bauer, P. Bechtold, A. C. M. Beljaars, L. van de Berg, J. Bidlot, N. Bormann, C. Delsol, R. Dragani, M. Fuentes, A. J. Geer, L. Haimberger, S. B. Healy, H. Hersbach, E. V. Hólm, L. Isaksen, P. Kållberg, M. Köhler, M. Matricardi, A. P. McNally, B. M. Monge-Sanz, J.-J. Morcrette, B.-K. Park, C. Peubey, P. de Rosnay, C. Tavolato, J.-N. Thépaut, and F. Vitart. The era-interim reanalysis: configuration and performance of the data assimilation system. Quarterly Journal of the Royal Meteorological Society, 137(656):553-597, 2011. ISSN 1477-870X. doi: 10.1002/qj.828. URL http://dx.doi .org/10.1002/qj . 828.

GMB Dobson. Origin and distribution of the polyatomic molecules in the atmosphere. Proceedings of the Royal Society of London. Series A, Mathematical and Physical Sciences, 236(1205):187-193, 1956.

Timothy Dunkerton. On the mean meridional mass motions of the stratosphere and mesosphere. Journal of the Atmospheric Sciences, 35(12):2325-2333, 1978.

Timothy J Dunkerton. Nonlinear hadley circulation driven by asymmetric differential heating. Journal of the atmospheric sciences, 46(7):956-974, 1989.

S. Fueglistaler, A. E. Dessler, T. J. Dunkerton, I. Folkins, Q. Fu, and P. W. Mote. Tropical tropopause layer. Reviews of Geophysics, 47(1), 2009. doi: 10.1029/2008RG000267.

A. Gettelman and T. Birner. Insights into tropical tropopause layer processes using global models. Journal of Geophysical Research: Atmospheres, 112(D23), 2007. doi: 10.1029/2007JD008945.

Andrew Gettelman, ML Salby, and F Sassi. Distribution and influence of convection in the tropical tropopause region. Journal of Geophysical Research: Atmospheres, 107(D10):ACL-6, 2002. 
PH Haynes, ME McIntyre, TG Shepherd, CJ Marks, and K Po Shine. On the "downward control" of extratropical diabatic circulations by eddy-induced mean zonal forces. Journal of the Atmospheric Sciences, 48(4):651-678, 1991.

Isaac M Held and Arthur Y Hou. Nonlinear axially symmetric circulations in a nearly inviscid atmosphere. Journal of the Atmospheric Sciences, 37(3):515-533, 1980.

Yvonne B. L. Hinssen and Maarten H. P. Ambaum. Relation between the 100-hpa heat flux and stratospheric potential vorticity. Journal of the Atmospheric Sciences, 67(12):4017-4027, 2010. doi: 10.1175/2010JAS3569.1. URL http://dx .doi .org/10.1175/2010JAS3569.1.

James R. Holton, Peter H. Haynes, Michael E. McIntyre, Anne R. Douglass, Richard B. Rood, and Leonhard Pfister. Stratosphere-troposphere exchange. Reviews of Geophysics, 33(4):403-439, 1995. doi: 10.1029/95RG02097.

Cameron R Homeyer and Kenneth P Bowman. Rossby wave breaking and transport between the tropics and extratropics above the subtropical jet. Journal of the Atmospheric Sciences, 70(2): 607-626, 2013.

Benjamin R. Johnston, Feiqin Xie, and Chuntao Liu. The effects of deep convection on regional temperature structure in the tropical upper troposphere and lower stratosphere. Journal of Geophysical Research: Atmospheres, 123(3):1585-1603, 2018. doi: 10.1002/2017JD027120.

P.W. Kållberg, P. Berrisford, B.J. Hoskins, A. Simmons, S. Uppala, S. Lamy-Thépaut, and R. Hine. Era-40 atlas. [note: Large pdf file: $68.3 \mathrm{mb}$; revised version posted 19.01.2006]. Shinfield Park, Reading, June 2005.

Jan A. Kamieniecki, Maarten H. P. Ambaum, Robert S. Plant, and Steven J. Woolnough. The implications of an idealized large-scale circulation for mechanical work done by tropical 
convection. Journal of the Atmospheric Sciences, 75(8):2533-2547, 2018. doi: 10.1175/ JAS-D-17-0314.1.

ME McIntyre and TN Palmer. The 'surf zone'in the stratosphere. Journal of atmospheric and terrestrial physics, 46(9):825-849, 1984.

AJ George Nurser and Mei-Man Lee. Isopycnal averaging at constant height. part i: The formulation and a case study. Journal of physical oceanography, 34(12):2721-2739, 2004.

Jonas Nycander, Johan Nilsson, Kristofer Döös, and Göran Broström. Thermodynamic analysis of ocean circulation. Journal of Physical Oceanography, 37(8):2038-2052, 2007.

Olivier Pauluis, Arnaud Czaja, and Robert Korty. The global atmospheric circulation in moist isentropic coordinates. Journal of Climate, 23(11):3077-3093, 2010.

R Alan Plumb. Stratospheric transport. Journal of the Meteorological Society of Japan. Ser. II, 80 (4B):793-809, 2002.

R Alan Plumb and Janusz Eluszkiewicz. The brewer-dobson circulation: Dynamics of the tropical upwelling. Journal of the atmospheric sciences, 56(6):868-890, 1999.

Tapio Schneider. The general circulation of the atmosphere. Annual Review of Earth and Planetary Sciences, 34(1):655-688, 2006. doi: 10.1146/annurev.earth.34.031405.125144.

MR Schoeberl, EJ Jensen, L Pfister, R Ueyama, T Wang, H Selkirk, M Avery, T Thornberry, and AE Dessler. Water vapor, clouds, and saturation in the tropical tropopause layer. Journal of Geophysical Research: Atmospheres, 124(7):3984-4003, 2019.

R. K. Scott and Y. S. Liu. On the formation and maintenance of the stratospheric surf zone as inferred from the zonally averaged potential vorticity distribution. Quarterly Journal of the Royal Meteorological Society, 141(687):327-332, 2014. doi: 10.1002/qj.2377. 
Kirill Semeniuk and Theodore G. Shepherd. Mechanisms for tropical upwelling in the stratosphere. Journal of the Atmospheric Sciences, 58(21):3097-3115, 2001. doi: 10.1175/ 1520-0469(2001)058<3097:MFTUIT>2.0.CO;2.

William JM Seviour, Neal Butchart, and Steven C Hardiman. The brewer-dobson circulation inferred from era-interim. Quarterly Journal of the Royal Meteorological Society, 138(665): 878-888, 2012.

Theodore G Shepherd. Transport in the middle atmosphere. Journal of the Meteorological Society of Japan. Ser. II, 85:165-191, 2007.

Daocheng Yu, Xiaohua Xu, Jia Luo, and Juan Li. On the relationship between gravity waves and tropopause height and temperature over the globe revealed by cosmic radio occultation measurements. Atmosphere, 10(2), 2019. ISSN 2073-4433. doi: 10.3390/atmos10020075. URL https : //www .mdpi.com/2073-4433/10/2/75.

Jan D Zika, Matthew H England, and Willem P Sijp. The ocean circulation in thermohaline coordinates. Journal of Physical Oceanography, 42(5):708-724, 2012. 


\section{${ }_{654}$ LIST OF TABLES}

655 Table 1. Definition of 4 areas used in the analysis . . . . . . . . . . . . . . 35 
TABLE 1. Definition of 4 areas used in the analysis

\begin{tabular}{l|cc} 
& MJ & ND \\
\hline Warm Extratropics & $90^{\circ} \mathrm{N}-30^{\circ} \mathrm{N}$ & $90^{\circ} \mathrm{S}-30^{\circ} \mathrm{S}$ \\
Tropics & $30^{\circ} \mathrm{S}-30^{\circ} \mathrm{N}$ \\
Surf Zone & $30^{\circ} \mathrm{S}-60^{\circ} \mathrm{S}$ & $30^{\circ} \mathrm{N}-60^{\circ} \mathrm{N}$ \\
Cold Pole & $60^{\circ} \mathrm{S}-90^{\circ} \mathrm{S}$ & $60^{\circ} \mathrm{N}-90^{\circ} \mathrm{N}$
\end{tabular}




\section{LIST OF FIGURES}

Fig. 1. Illustration of the budget equations (7), (12) and (13) for the internal energy $I$, the potential energy $U$ and the kinetic energy $K$. The energy fluxes are defined as positive in the direction of the arrows.

Fig. 2. Sketch of the stream function $\Psi$ with the specific volume $\alpha$ and the pressure $p$ as coordinates.

Fig. 3. Annual mean stream function $\Psi$ (contours drawn at $\pm 0.2,0.5,1,2,5,10,20,50,100$, $20010^{8} \mathrm{Kg} \mathrm{s}^{-1}$ ). Arrows indicate qualitatively the direction of motion. Yellow arrows are referred to the positive part of the stream function, green arrows are referred to the negative part.

Fig. 4. Annual mean of advective vertical sensible heat flux computed by the integral of $\Psi$ over temperature (black line). The red and blue lines correspond respectively to the heat flux of the direct cell and the indirect cell, obtained integrating $\Psi$ respectively only where $\Psi>0$ and $\Psi<0$

Fig. 5. Seasonal cycle at selected levels of the stream fucntion and the RMS of the vertical massflux deduced from the stream function. a) Seasonal cycle of $\Psi$ at $5 \mathrm{hPa}\left(10^{8} \mathrm{Kg} \mathrm{s}^{-1}\right)$. b) Seasonal cycle of RMS of the derivative of the stream function with respect to temperature $\left(10^{7} \mathrm{Kg} \mathrm{s}^{-1} \mathrm{~K}^{-1}\right)$. c) and d) as in a-b but at $20 \mathrm{hPa}$ e) and f) as in a-b but at $125 \mathrm{hPa}$.

Fig. 6. Seasonal cycle of the stream function maximum at three pressure levels, namely 5, 20 and $125 \mathrm{hPa}$.

Fig. 7. As in Fig.6 but for the stream function minimum.

Fig. 8. Eddy poleward heat flux at $100 \mathrm{hPa}$ averaged respectively over $40-80{ }^{\circ} \mathrm{N}$ (blue line), 40-80 ${ }^{\circ} \mathrm{S}$ (red line), and their sum (black line). Units are $\mathrm{K} \cdot \mathrm{m} / \mathrm{s}$, solid lines are the 1994-2015 medians, shadings indicate the interquartile range.

Fig. 9. Logarithm of mass density $\Phi$ (colors, dimensionless) and mass flux density (contours, $10^{7}$ $\mathrm{Kg} \mathrm{K}^{-1} \mathrm{~s}^{-1}$, solid lines for positive values and dashed lines for negative values.) for MJ (top) and ND (bottom). Dotted lines are dry isentropes labelled with potential temperature in $\mathrm{K}$.

Fig. 10. Stream function $\Psi$ (contours, drawn at $\pm 0.2,0.5,1,2,5,10,20,50,10^{8} \mathrm{Kg} \mathrm{s}^{-1}$ ), solid lines for positive values and dashed lines for negative values.) and mass-weighted absolute value of latitude for MJ (top) and ND (bottom). Dotted lines are dry isentropes labelled with potential temperature in $\mathrm{K}$.

Fig. 11. Latitude-pressure cross section for zonally averaged temperature (colors, K) for MJ (top) and ND (bottom). Solid lines are dry isentropes labelled with potential temperature in K.

Fig. 12. Normalised mass densities of the 4 regions indicated in table 1 for MJ (top) and ND (bottom). The mass density is normalised to integrate to one at each level. Contours are drawn at 0.002 .

Fig. 13. a) Logarithm of mass densities at $10 \mathrm{hPa}$ for the cold extratropics (the sum of the surf zone and the cold pole) (blue line) and for the warm extratropics (red line). b) As in a) but for the 
mass weighted lagrangian pressure tendency (vertical velocity, $\mathrm{Pa} \mathrm{s}^{-1}$, negative downward).

c) As in a) but for the vertical mass flux. All values are for ND.

Fig. 14. Difference between $N D$ and $M J$ for the stream function $\Psi$ (contours drawn at $\pm 0.2,0.5,1$, 2, 5, 10, 20, $10^{8} \mathrm{Kg} \mathrm{s}^{-1}$ ). Dotted lines are dry isentropes labelled with potential temperature in $\mathrm{K}$. 


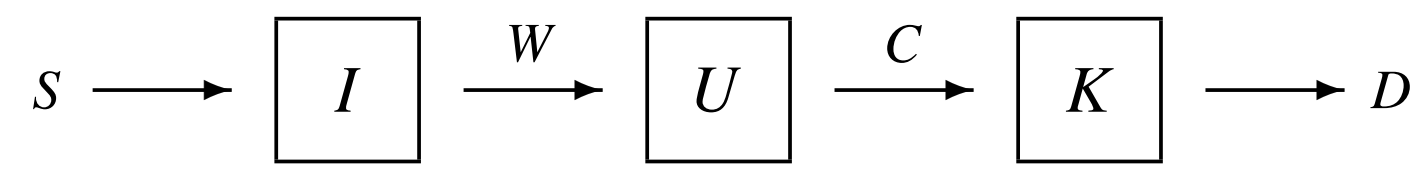

FIG. 1. Illustration of the budget equations (7), (12) and (13) for the internal energy $I$, the potential energy $U$ and the kinetic energy $K$. The energy fluxes are defined as positive in the direction of the arrows. 


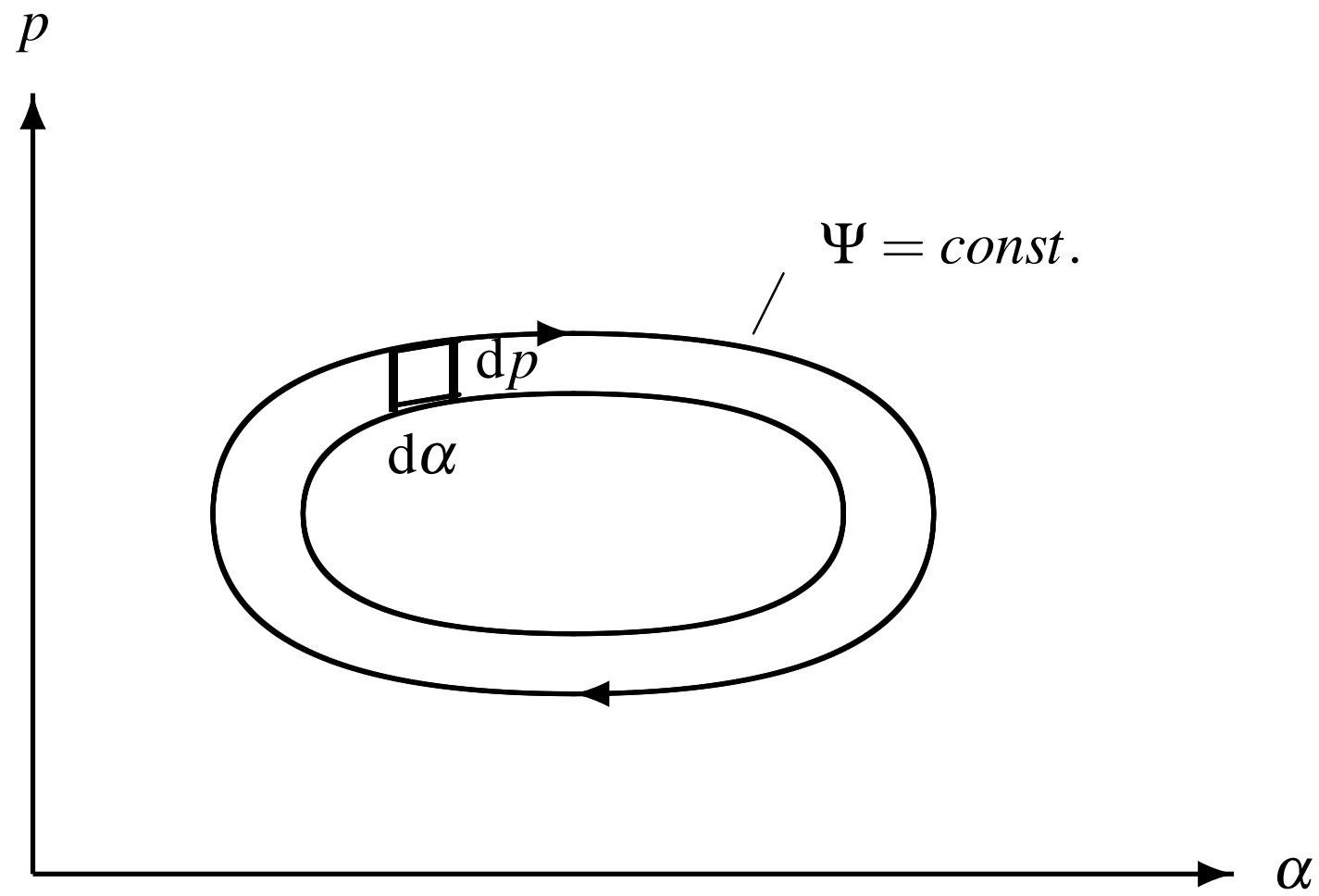

FIG. 2. Sketch of the stream function $\Psi$ with the specific volume $\alpha$ and the pressure $p$ as coordinates. 


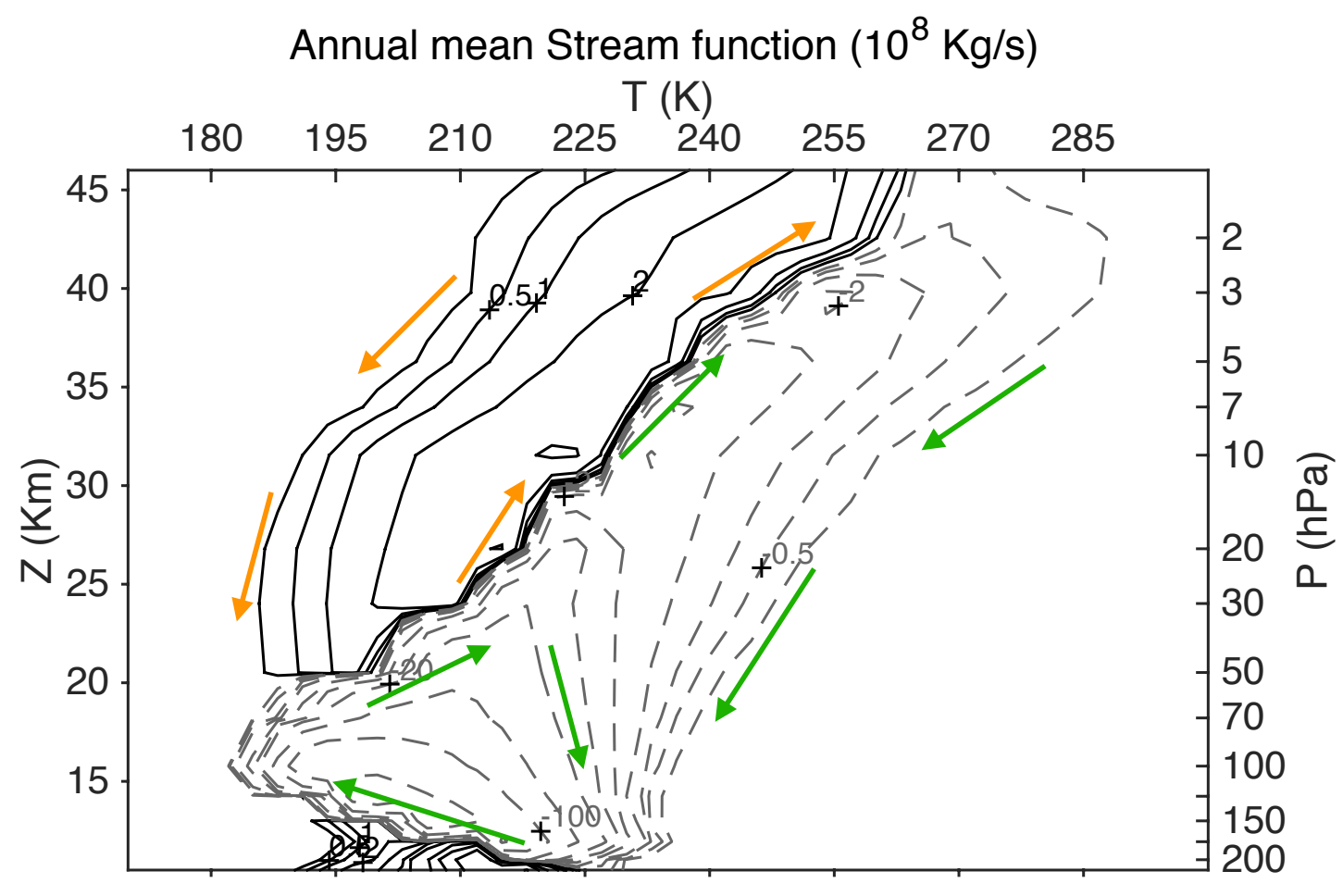

FIG. 3. Annual mean stream function $\Psi$ (contours drawn at $\pm 0.2,0.5,1,2,5,10,20,50,100,20010^{8} \mathrm{Kg}$ $\mathrm{s}^{-1}$ ). Arrows indicate qualitatively the direction of motion. Yellow arrows are referred to the positive part of the stream function, green arrows are referred to the negative part. 


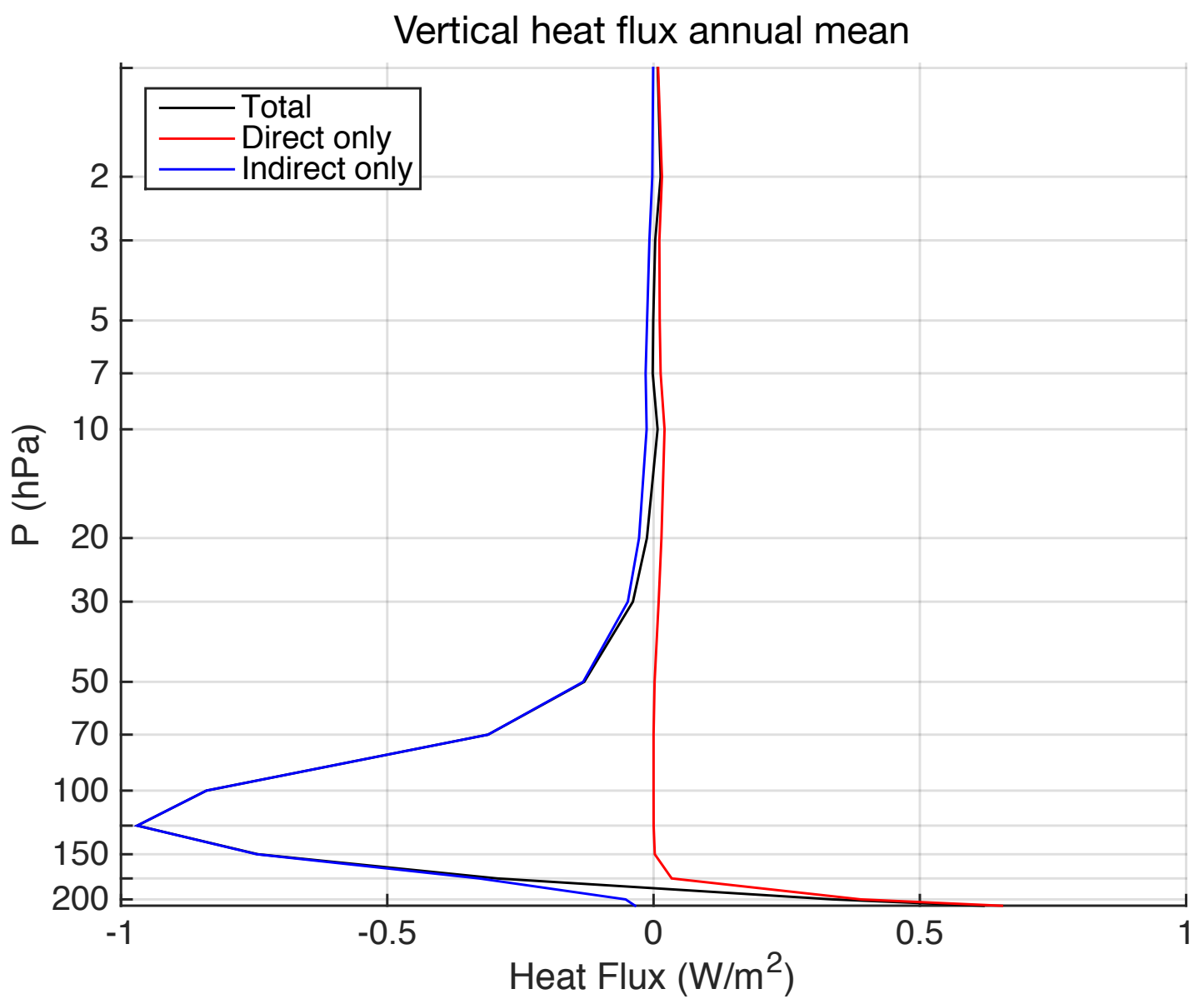

FIG. 4. Annual mean of advective vertical sensible heat flux computed by the integral of $\Psi$ over temperature (black line). The red and blue lines correspond respectively to the heat flux of the direct cell and the indirect cell, obtained integrating $\Psi$ respectively only where $\Psi>0$ and $\Psi<0$ 
a) Stream function at $5 \mathrm{hPa}$

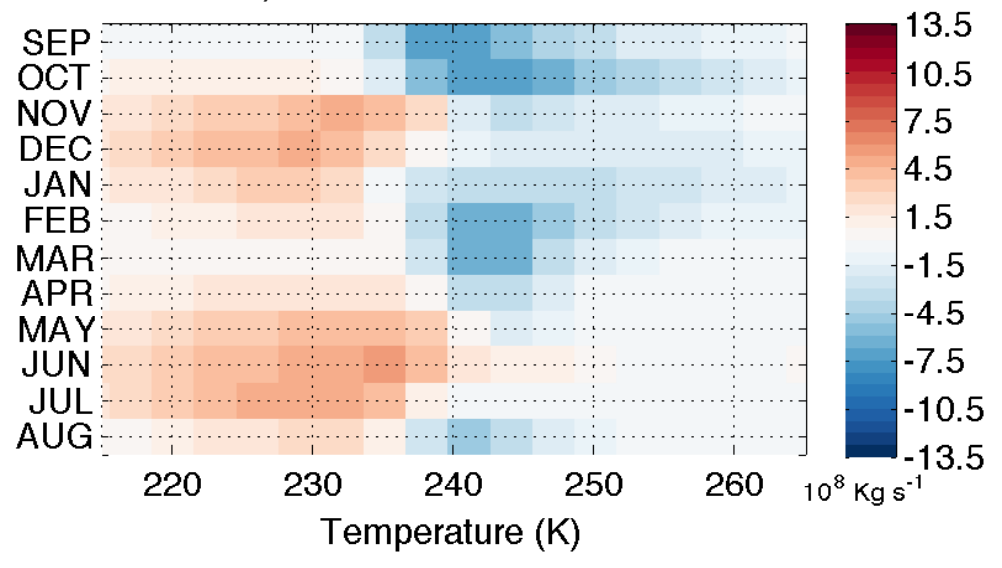

C) Stream function at $20 \mathrm{hPa}$

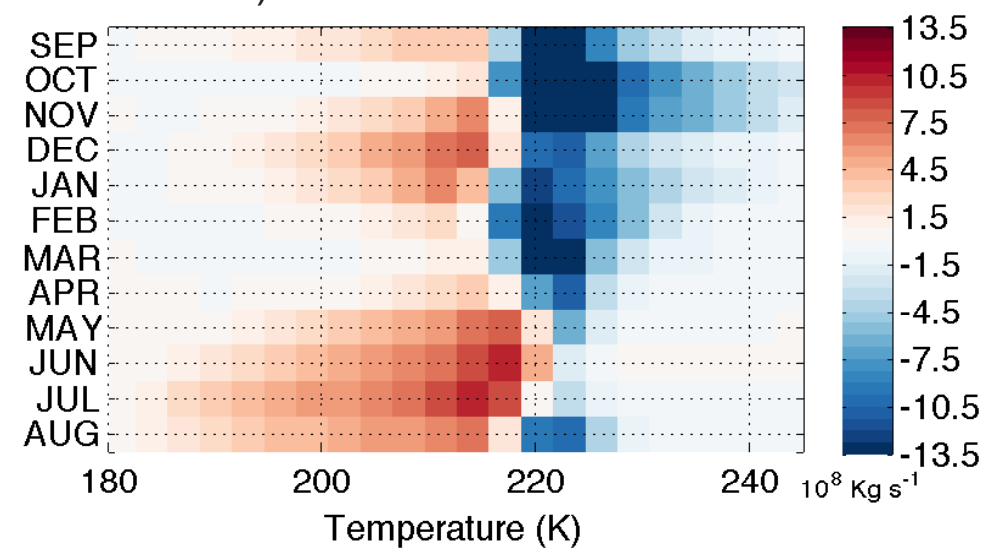

e) Stream function at $125 \mathrm{hPa}$

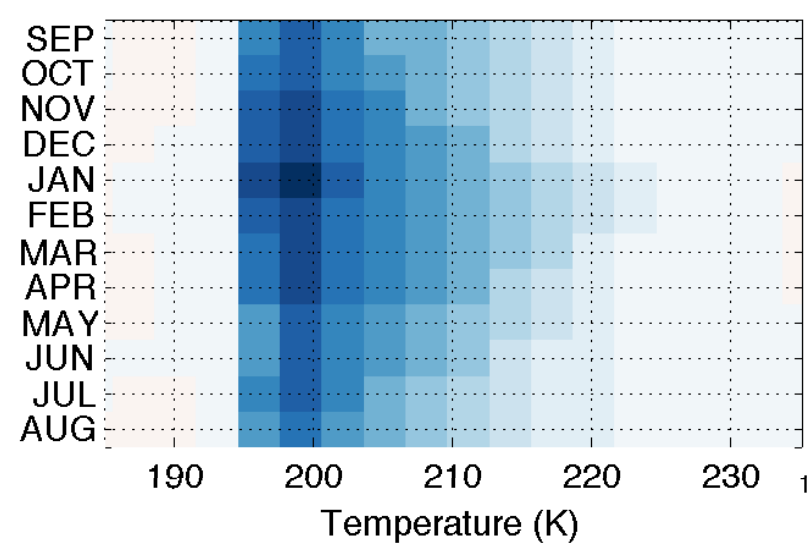

b) $\sqrt{\left\langle\left(\frac{\delta \Psi}{\delta T}\right)^{2}\right\rangle}$

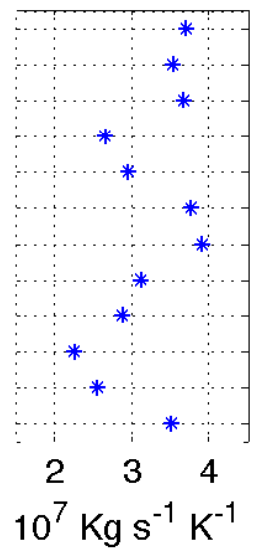

d) $\sqrt{\left\langle\left(\frac{\delta \Psi}{\delta T}\right)^{2}\right\rangle}$

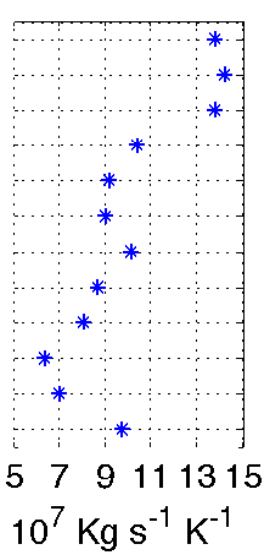

f) $\sqrt{\left\langle\left(\frac{\delta \Psi}{\delta T}\right)^{2}\right\rangle}$

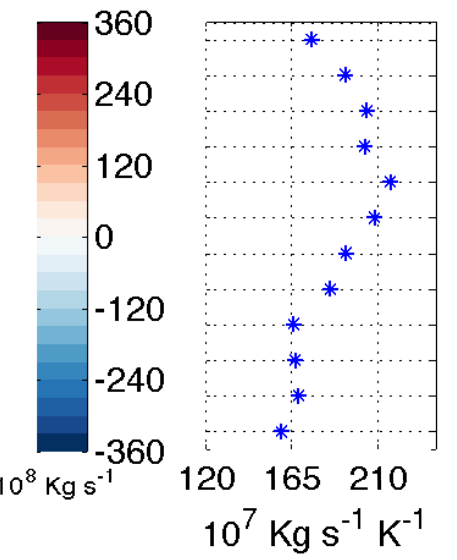

FIG. 5. Seasonal cycle at selected levels of the stream fucntion and the RMS of the vertical mass-flux deduced from the stream function. a) Seasonal cycle of $\Psi$ at $5 \mathrm{hPa}\left(10^{8} \mathrm{Kg} \mathrm{s}^{-1}\right)$. b) Seasonal cycle of RMS of the derivative of the stream function with respect to temperature $\left(10^{7} \mathrm{Kg} \mathrm{s}^{-1} \mathrm{~K}^{-1}\right)$. c) and d) as in a-b but at $20 \mathrm{hPa}$ e) and f) as in a-b but at $125 \mathrm{hPa}$. 
$\Psi$ maximum at constant pressure
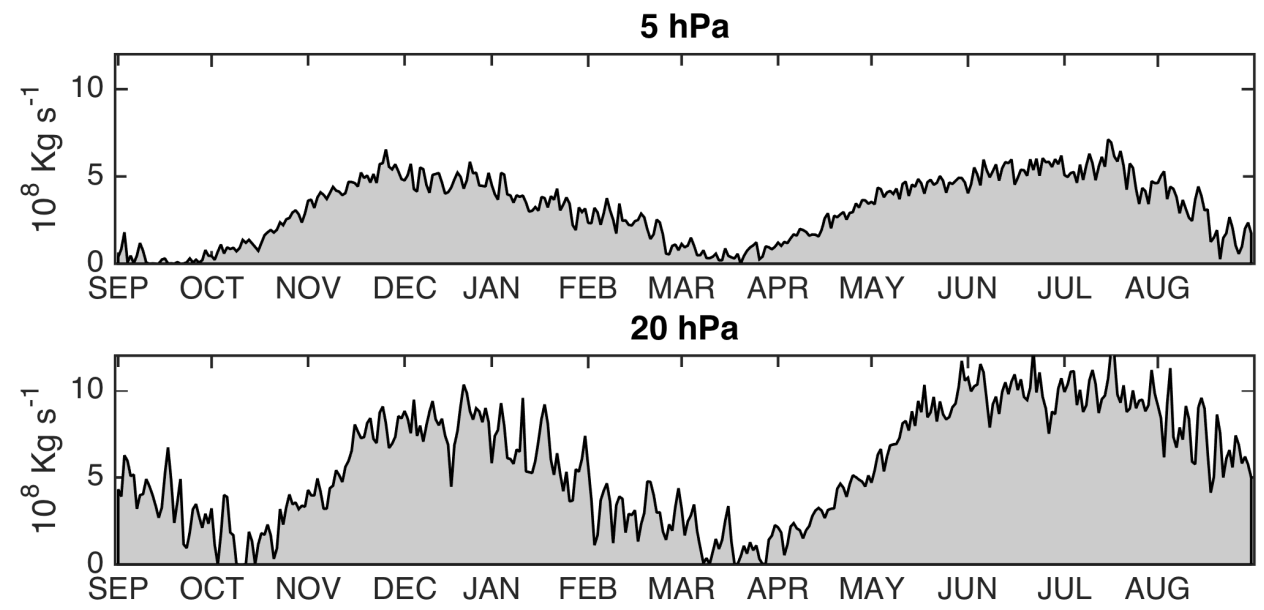

$125 \mathrm{hPa}$

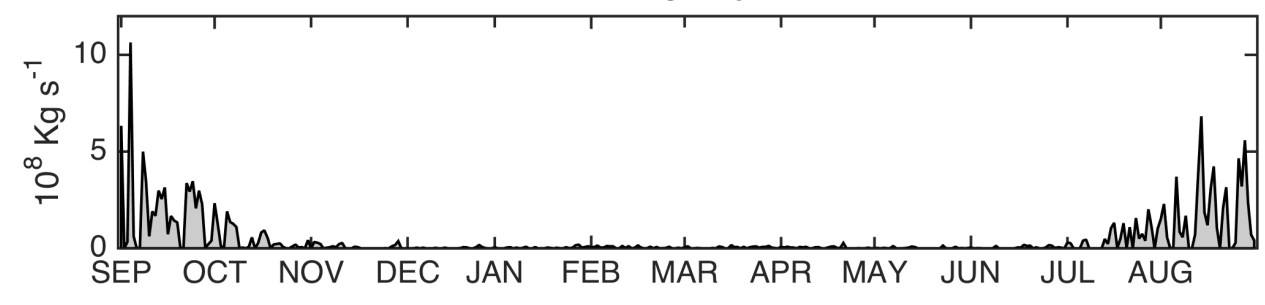

FIG. 6. Seasonal cycle of the stream function maximum at three pressure levels, namely 5, 20 and $125 \mathrm{hPa}$. 
$\Psi$ minimum at constant pressure
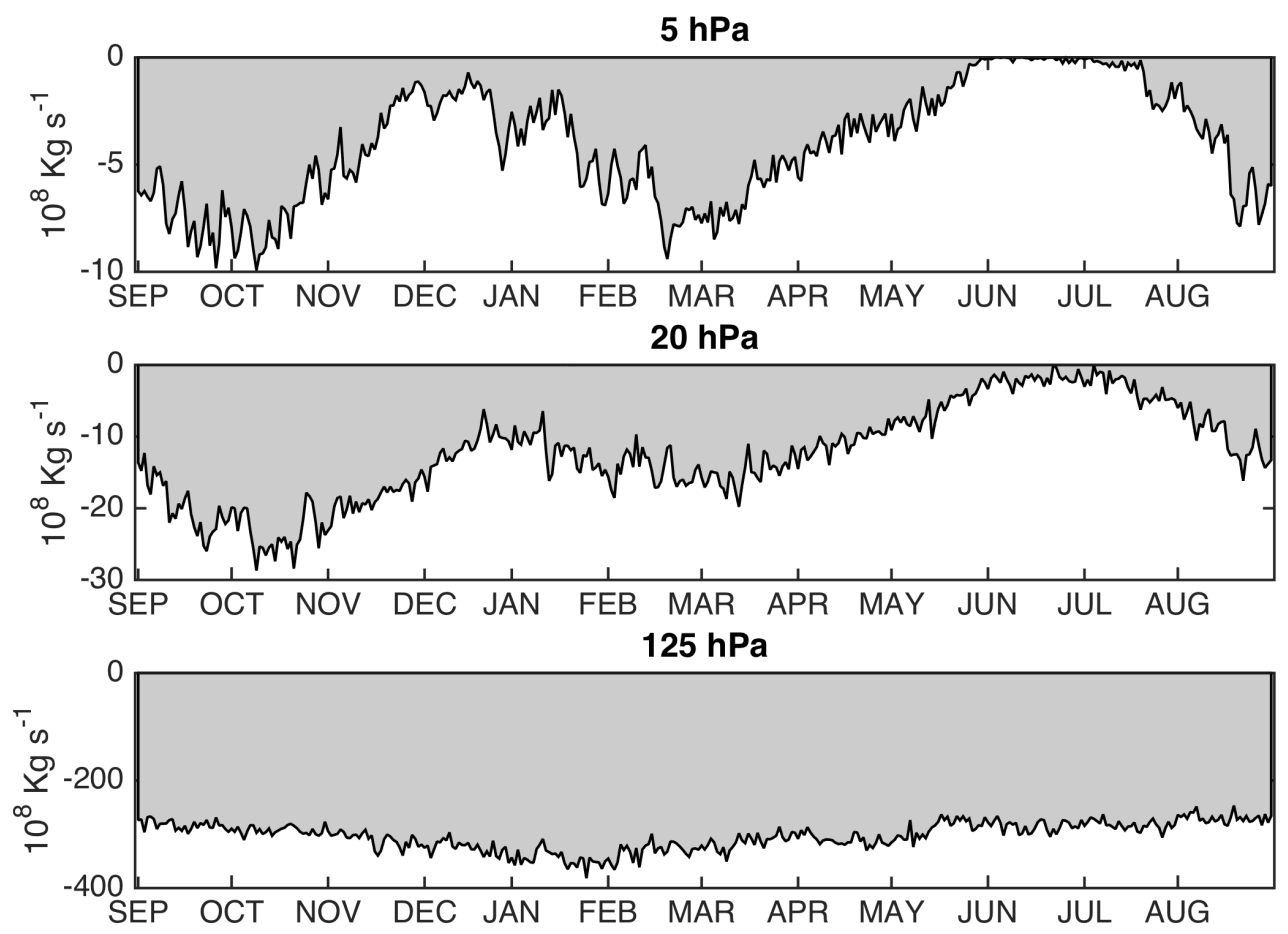

FIG. 7. As in Fig.6 but for the stream function minimum. 


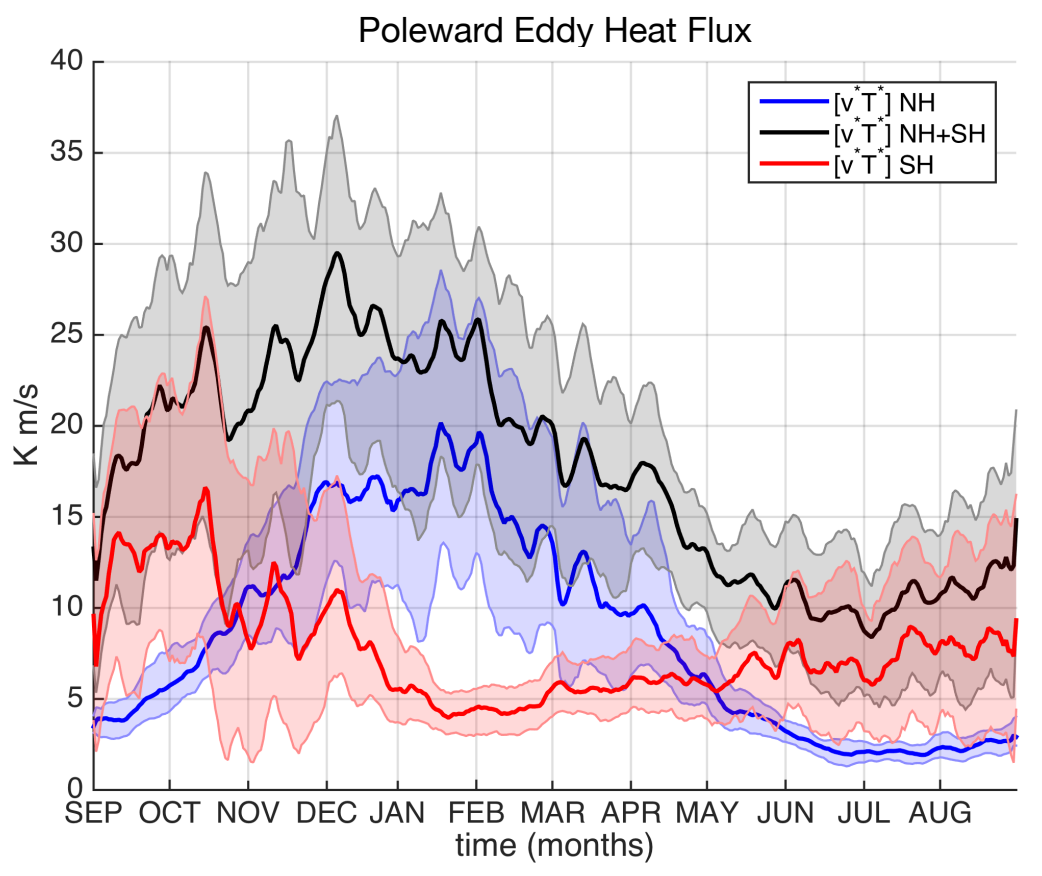

FIG. 8. Eddy poleward heat flux at $100 \mathrm{hPa}$ averaged respectively over $40-80{ }^{\circ} \mathrm{N}$ (blue line), $40-80{ }^{\circ} \mathrm{S}$ (red line), and their sum (black line). Units are K·m/s, solid lines are the 1994-2015 medians, shadings indicate the interquartile range. 


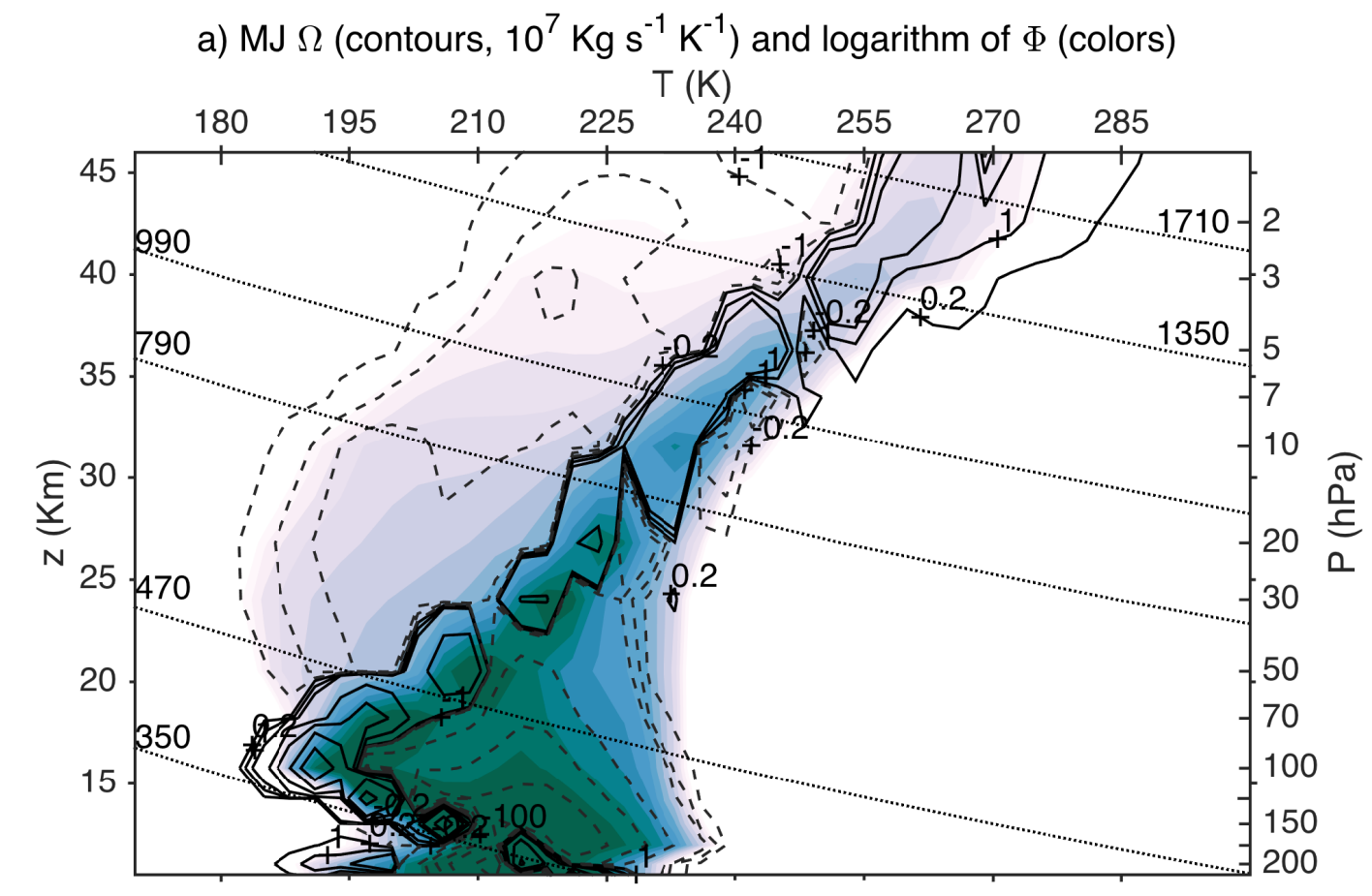

b) ND $\Omega$ (contours, $10^{7} \mathrm{Kg} \mathrm{s}^{-1} \mathrm{~K}^{-1}$ ) and logarithm of $\Phi$ (colors)

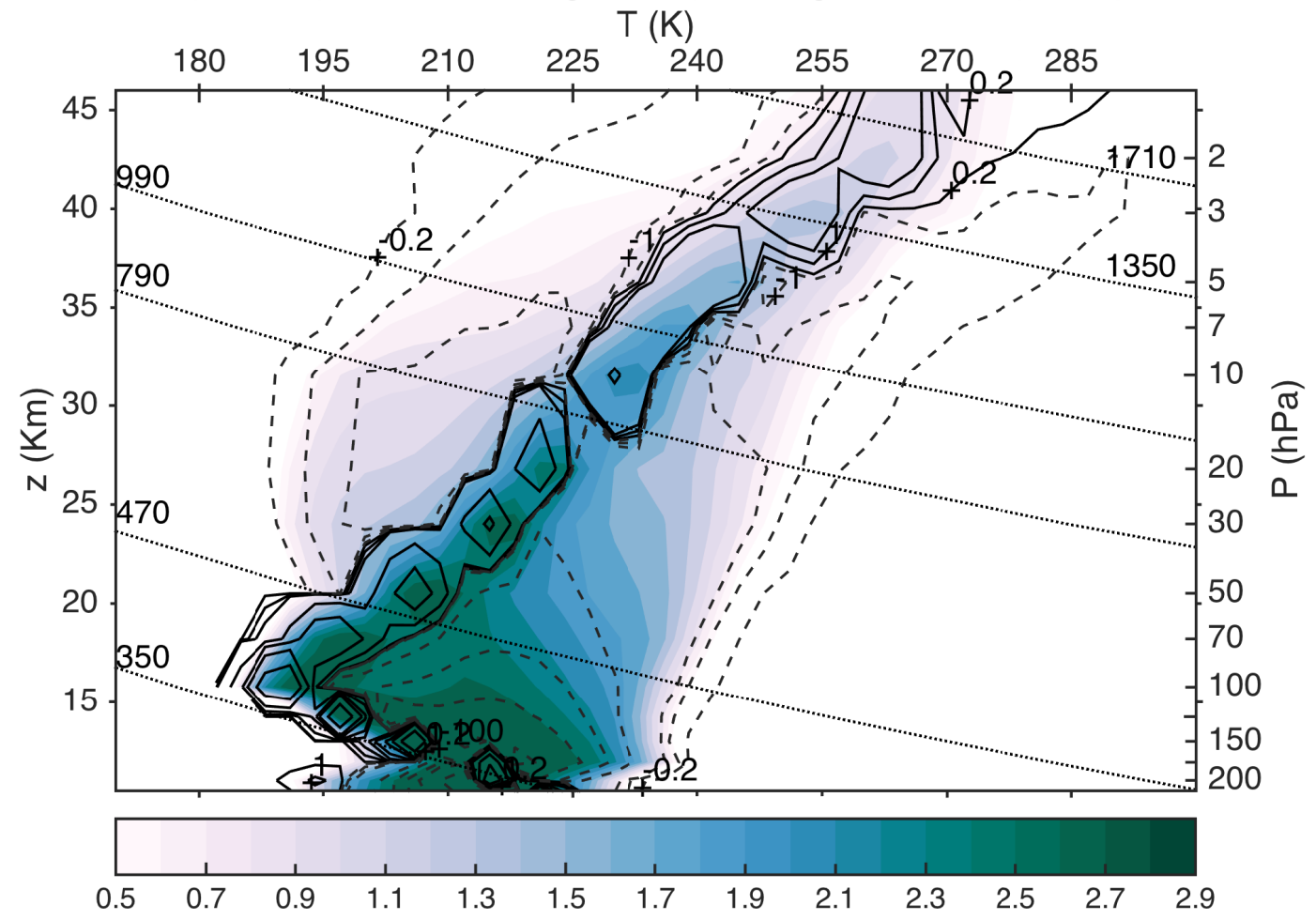

FIG. 9. Logarithm of mass density $\Phi$ (colors, dimensionless) and mass flux density (contours, $10^{7} \mathrm{Kg} \mathrm{K}^{-1}$ $716 \mathrm{~S}^{-1}$, solid lines for positive values and dashed lines for negative values.) for MJ (top) and ND (bottom). Dotted 717 lines are dry isentropes labelled with potential temperature in $\mathrm{K}$. 


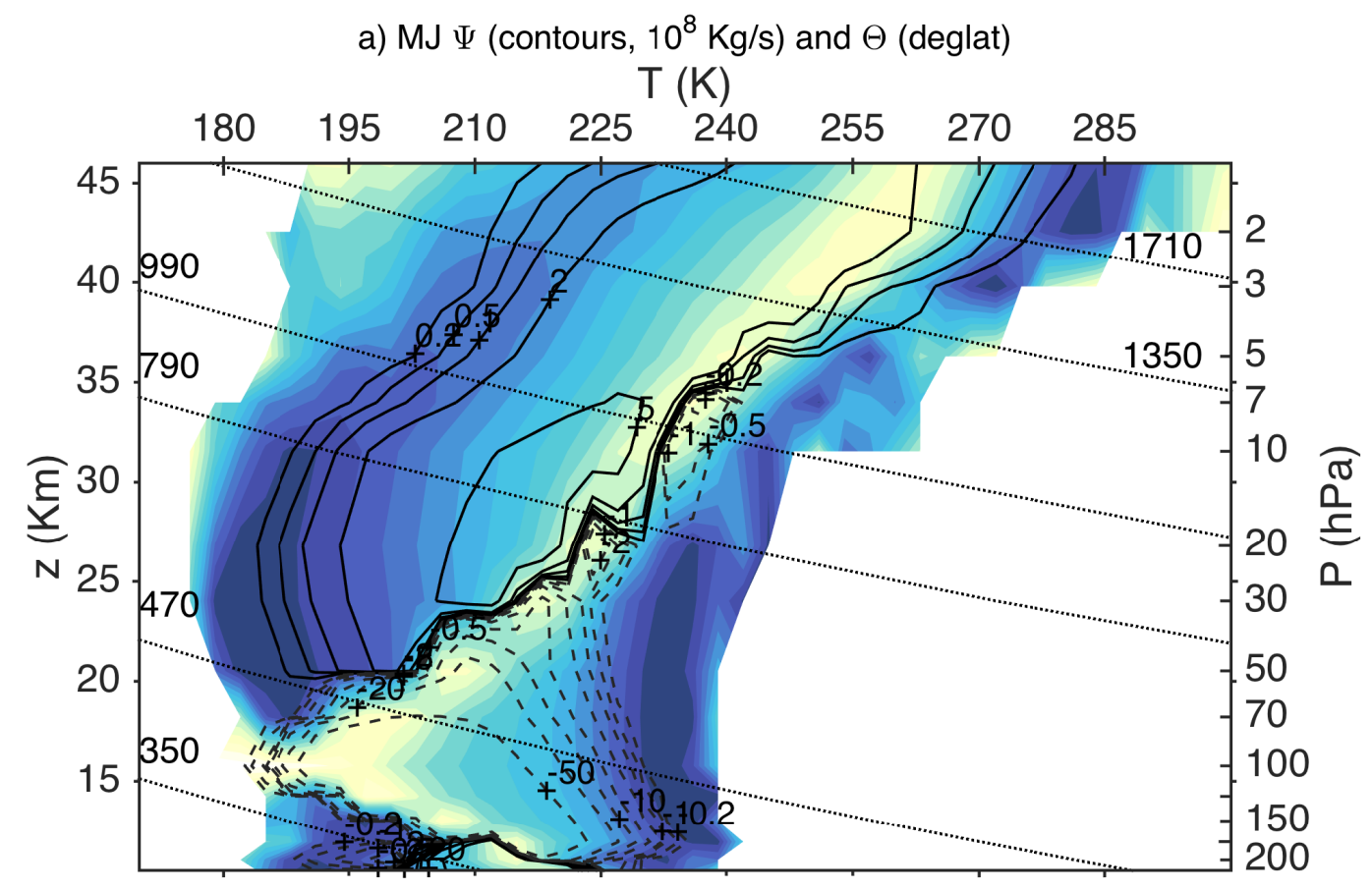

b) ND $\Psi$ (contours, $10^{8} \mathrm{Kg} / \mathrm{s}$ ) and $\Theta$ (deglat)
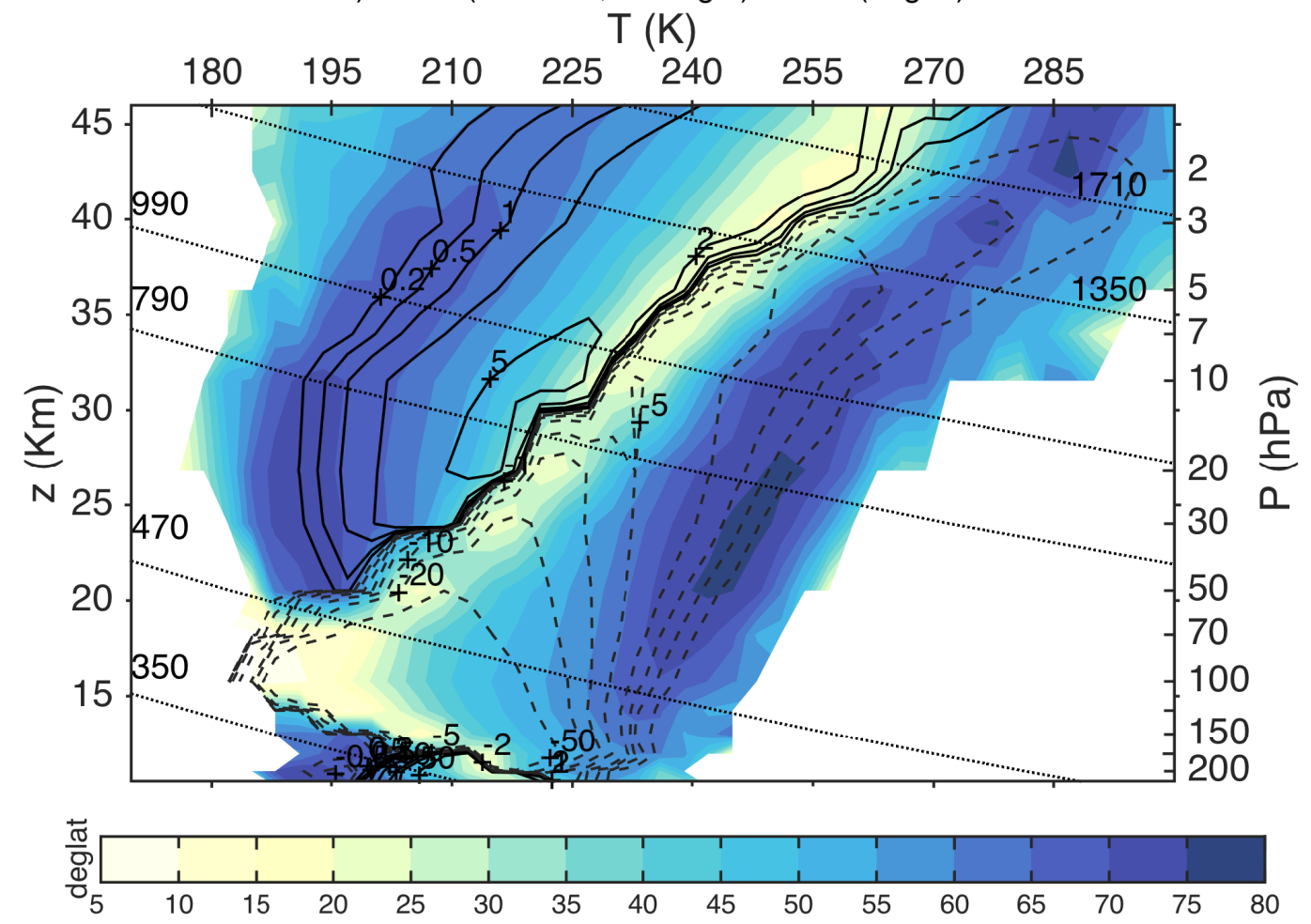

FIG. 10. Stream function $\Psi$ (contours, drawn at $\pm 0.2,0.5,1,2,5,10,20,50,10^{8} \mathrm{Kg} \mathrm{s}^{-1}$ ), solid lines for 

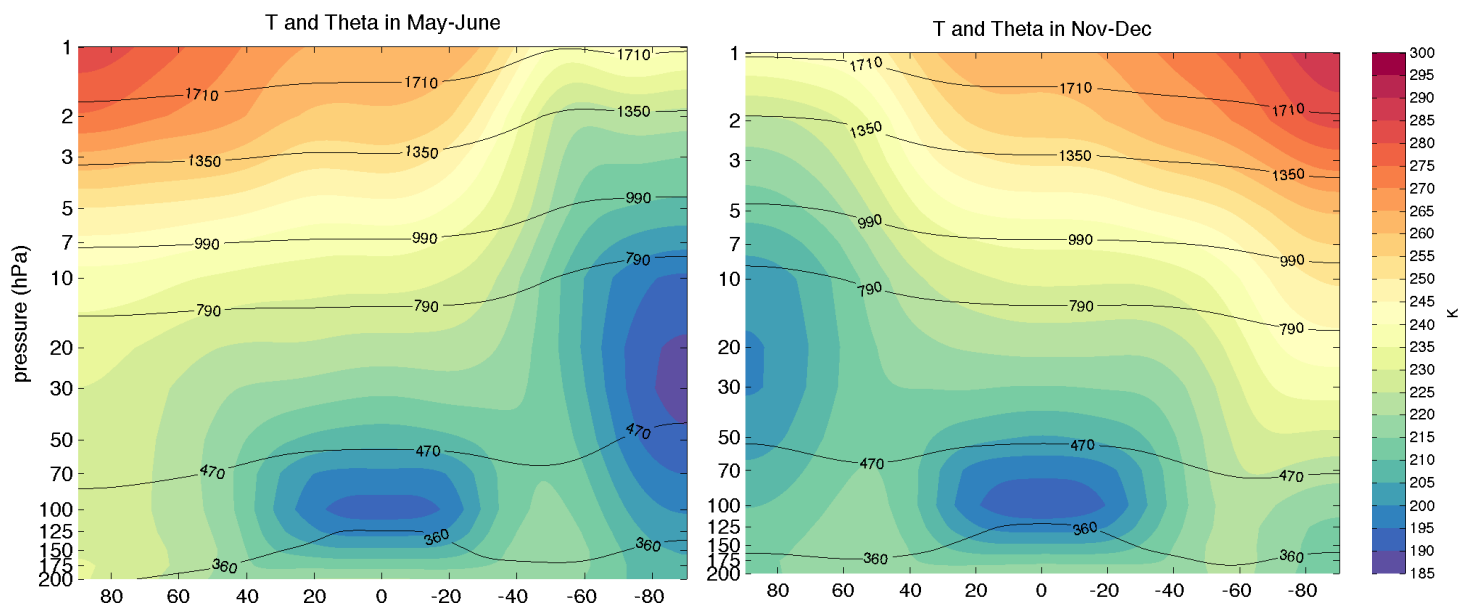

FIG. 11. Latitude-pressure cross section for zonally averaged temperature (colors, K) for MJ (top) and ND 722 (bottom). Solid lines are dry isentropes labelled with potential temperature in K. 

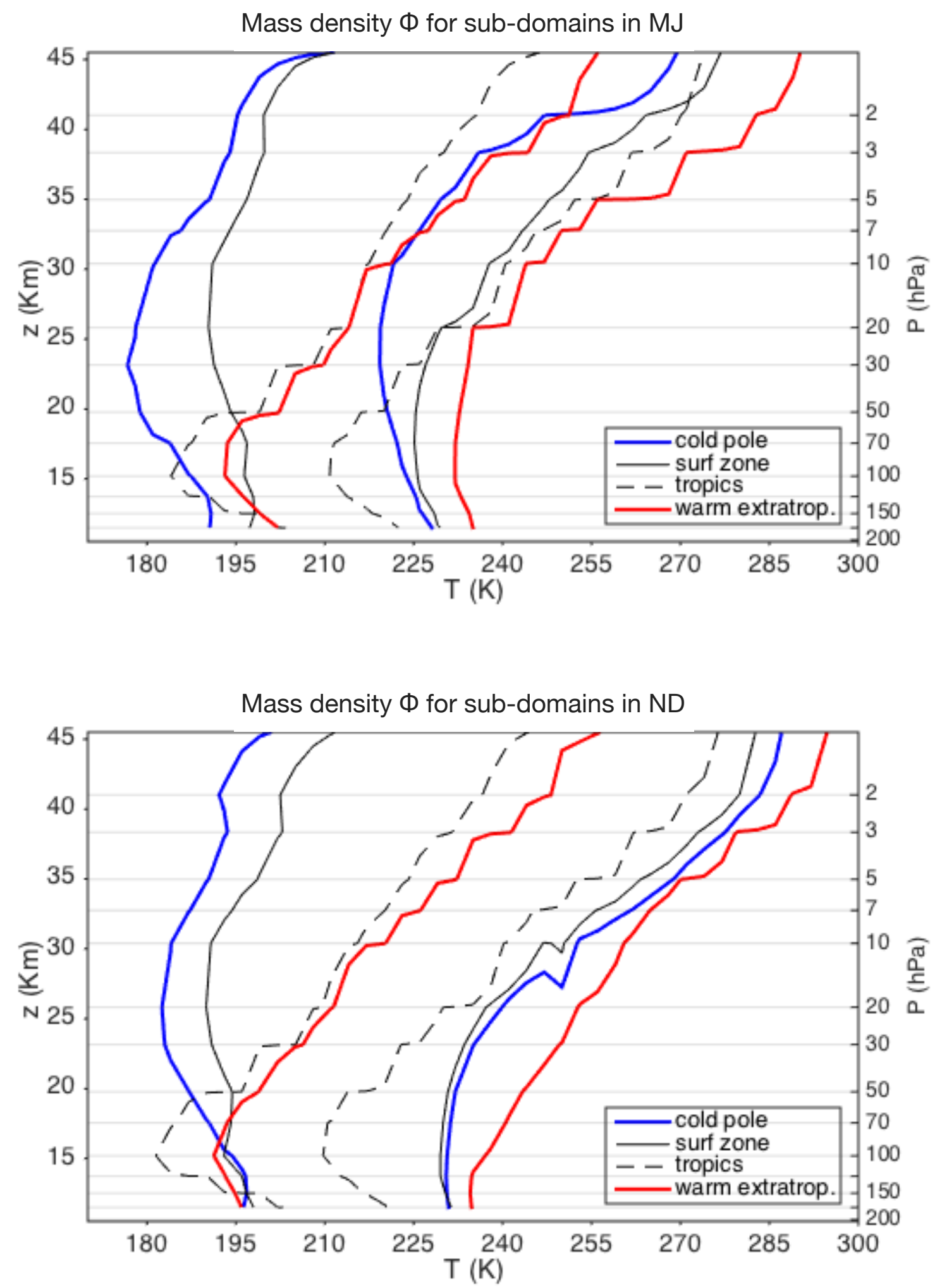

FIG. 12. Normalised mass densities of the 4 regions indicated in table 1 for MJ (top) and ND (bottom). The 724 mass density is normalised to integrate to one at each level. Contours are drawn at 0.002 . 
a) Logarithm of mass density (adim.)
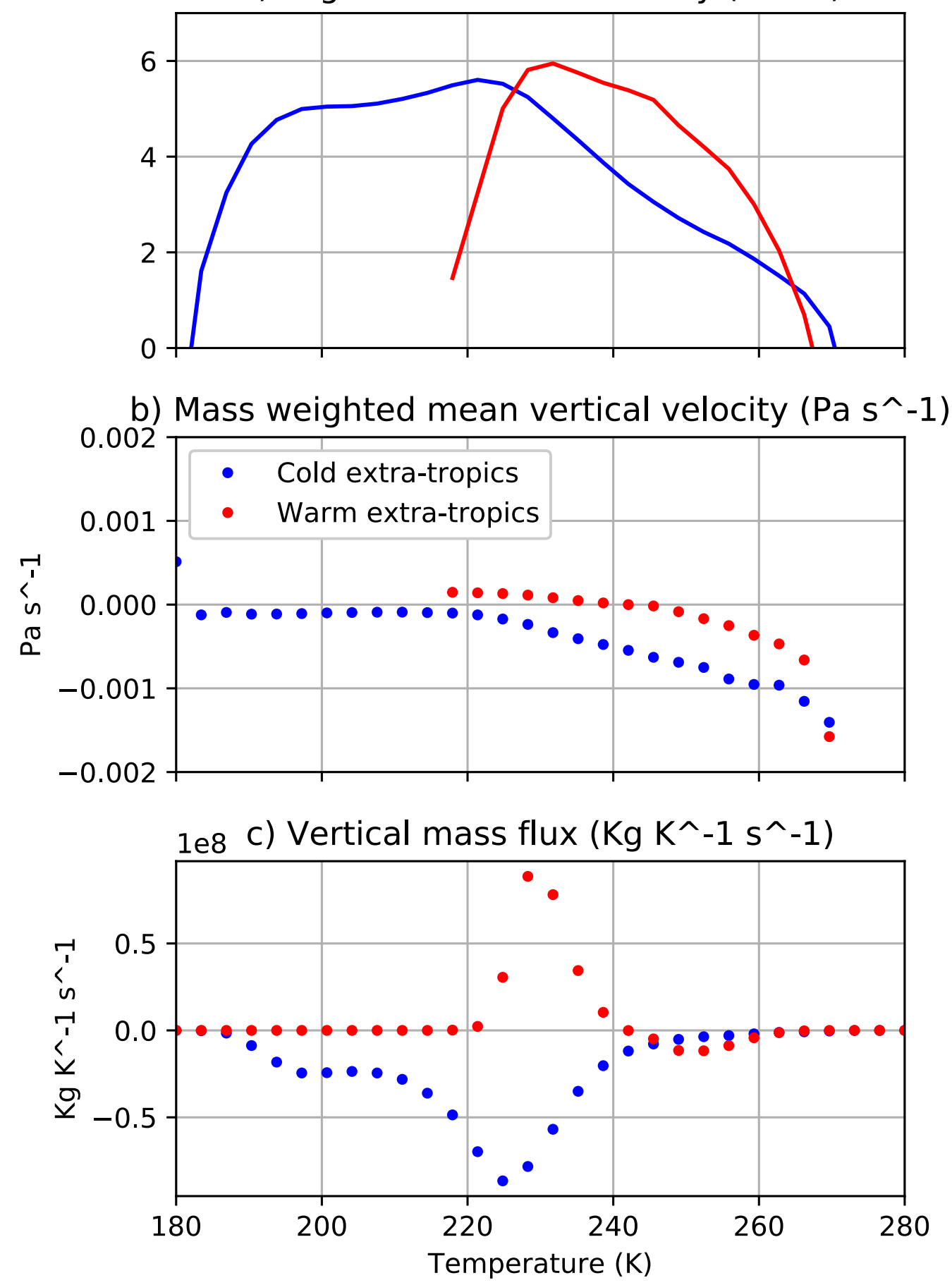

FIG. 13. a) Logarithm of mass densities at $10 \mathrm{hPa}$ for the cold extratropics (the sum of the surf zone and the cold pole) (blue line) and for the warm extratropics (red line). b) As in a) but for the mass weighted lagrangian pressure tendency (vertical velocity, $\mathrm{Pa} \mathrm{s}^{-1}$, negative downward). c) As in a) but for the vertical mass flux. All values are for ND. 


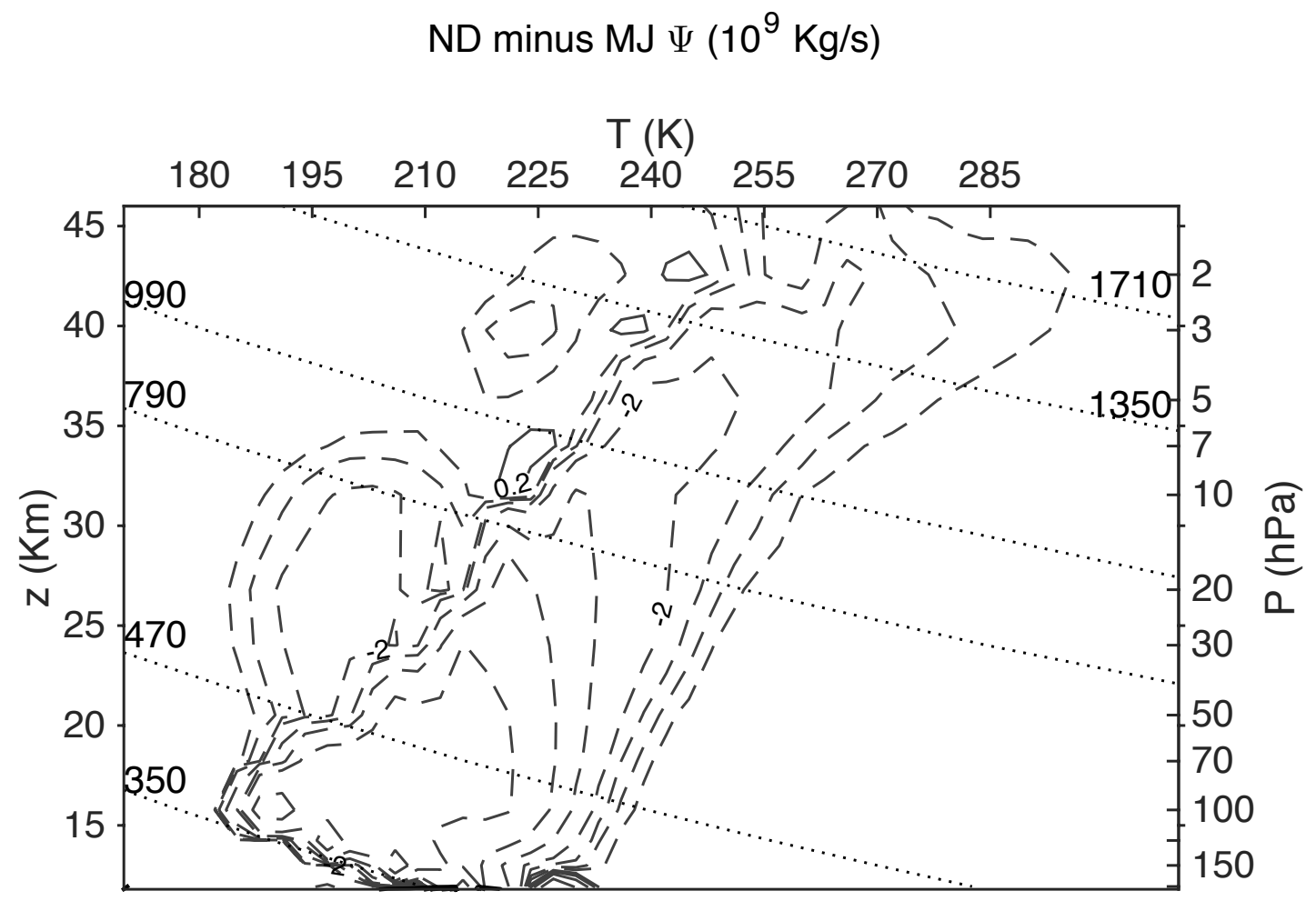

FIG. 14. Difference between ND and MJ for the stream function $\Psi$ (contours drawn at $\pm 0.2,0.5,1,2,5,10$, $20,10^{8} \mathrm{Kg} \mathrm{s}^{-1}$ ). Dotted lines are dry isentropes labelled with potential temperature in $\mathrm{K}$. 